\title{
A Comparative Study on Frequency Sensitivity of a Transmission Tower
}

\author{
Peng-yun Li, ${ }^{1}$ Bo Chen, ${ }^{2}$ Wen-ping Xie, ${ }^{1}$ and Xiang Xiao ${ }^{3}$ \\ ${ }^{1}$ Guangdong Power Grid Corporation Co. Ltd., Guangzhou 510080, China \\ ${ }^{2}$ Key Laboratory of Roadway Bridge and Structural Engineering, Wuhan University of Technology, Wuhan 430070, China \\ ${ }^{3}$ School of Transportation, Wuhan University of Technology, Wuhan 430070, China \\ Correspondence should be addressed to Bo Chen; cbsteven@163.com
}

Received 15 November 2014; Accepted 25 December 2014

Academic Editor: Fei Dai

Copyright (c) 2015 Peng-yun Li et al. This is an open access article distributed under the Creative Commons Attribution License, which permits unrestricted use, distribution, and reproduction in any medium, provided the original work is properly cited.

Sensitivity analysis can take structural parameters as variable and achieve the relationship only with one time analysis, which will dramatically reduce the analytical work especially for large scale structures. The comparative study on frequency sensitivity of a transmission tower is actively carried out in this study. The three-dimensional analytical model of a transmission tower is established by using the finite element (FE) method. The sensitivity coefficients to natural frequencies are deduced based on the equation of motion of the tower. In addition, the expression of the frequency sensitivity to Young's modulus, density of material, the cross area of members, torsional stiffness, and bending moment inertia is proposed. A real transmission tower constructed in China is taken as an example to examine the feasibility and reliability of the proposed sensitivity computation approach. An intensive parametric study is conducted in detail in order to compare the sensitivity coefficients of different physical parameters. The work on an example structure indicated that the magnitudes of the sensitivity coefficients of Young's modulus, the density, and the cross area are much larger than those of the torsional stiffness and the bending moment inertia.

\section{Introduction}

To be a typical spatial steel structure, the transmission tower is widely used as electrical power infrastructures throughout the world. The transmission tower is a high-rise structure with small damping and is prone to strong dynamic excitations, such as earthquakes and wind loadings [1-3]. It is frequently reported across the world that the excessive vibration of a transmission tower under dynamic excitations may induce the structural damage and even failure [4-6]. Therefore, it is necessary to evaluate the structural performance of the transmission tower subjected to external dynamic excitations. Many theoretical and experimental investigations have been carried out during the past two decades for examining the performance of the transmission tower $[7,8]$. With regard to the approaches and techniques used for performance evaluation, the transmission tower system is conventionally designed and constructed using appropriate design standards without considering the dynamic optimization effects. Therefore, the common approach does not provide deep insights into the structural transient behaviour under strong dynamic excitations, even though the consideration of dynamic effects may be important. Thus, the vibration-based structural health monitoring (SHM) approaches have been widely utilized in the performance evaluation of civil engineering structures across the world [9-11]. The SHM process needs to develop or improve a mathematical model of a physical system using measurement data to describe the input, output, and noise relationship [12,13]. Various methods have been developed to improve the quality of the finite element model of a structure using measurement data [14]. Doebling et al. (1998) [15] gave a comprehensive review on SHM. With regard to the different SHM algorithm used, the effects of various physical parameters on the structural responses can be examined in detail to determine the crucial parameters for structural dynamic design and assessment.

For a transmission tower with determined parameters, it is troublesome to attain the relationship between dynamic characteristics and changed parameters by numerous recalculations which will be almost impossible for large 
scale structures, while sensitivity analysis as an alternative approach can take structural parameters as variable and achieve the relationship only with one time analysis, which will dramatically reduce the analytical work especially for large scale structures [16]. The sensitivity analysis is a reasonable and powerful tool for investigating the effects of physical parameters on static and dynamic responses. The sensitivity analysis concerns the relationship between parameters available to the structural responses under dynamic excitations. The dependence of response measures, such as displacement, velocity, acceleration, stress, strain, natural frequency, mode shape, and frequency response, is implicitly defined through the governing equations of structural mechanics [17]. Dynamic sensitivity analysis is used to compute the rate of dynamic property change with respect to changes of structural physical parameters.

Current studies on the dynamic assessment of the transmission tower focus on the response computation and mitigation. Up to now, the sensitivity analysis of the transmission tower for dynamic assessment has been investigated rarely. To this end, the comparative study on frequency sensitivity of a transmission tower is actively carried out in this study. The three-dimensional model of a transmission tower is established by using the FE method. The differential sensitivity analysis approach is presented based on the differential sensitivity coefficient, the absolute sensitivity coefficient, and the relative sensitivity coefficient, respectively. The sensitivity coefficients to natural frequencies are deduced based on the equation of motion of the tower. In addition, the expression of the frequency sensitivity to the Young's modulus, density of material, the cross area of members, torsional stiffness, and bending moment inertia is proposed. A real transmission tower is taken as the example to investigate the effects of the structural parameters on the natural frequency through the detailed parametric study. An intensive parametric study is conducted to compare the sensitivity coefficients of different physical parameters. A real transmission tower constructed in China is taken as an example to examine the feasibility and reliability of the proposed sensitivity computation approach. The observations made indicate that the magnitudes of the sensitivity coefficients of the Young's modulus, the density and the cross area are much larger than those of the torsional stiffness and the bending moment inertia. The Young's modulus, the density and the cross area are important structural parameters affecting the dynamic properties of the transmission tower.

\section{Model of Transmission Tower}

A transmission tower is a typical truss structure constructed by using steel members, which can be commonly modelled by using beam elements based on the finite element (FE) method $[18,19]$. For an Euler-Bernoulli beam element, stiffness matrix of the $i$ th element of a transmission tower in the local coordinate system (LCS) $\mathbf{K}_{i}^{e}$ is

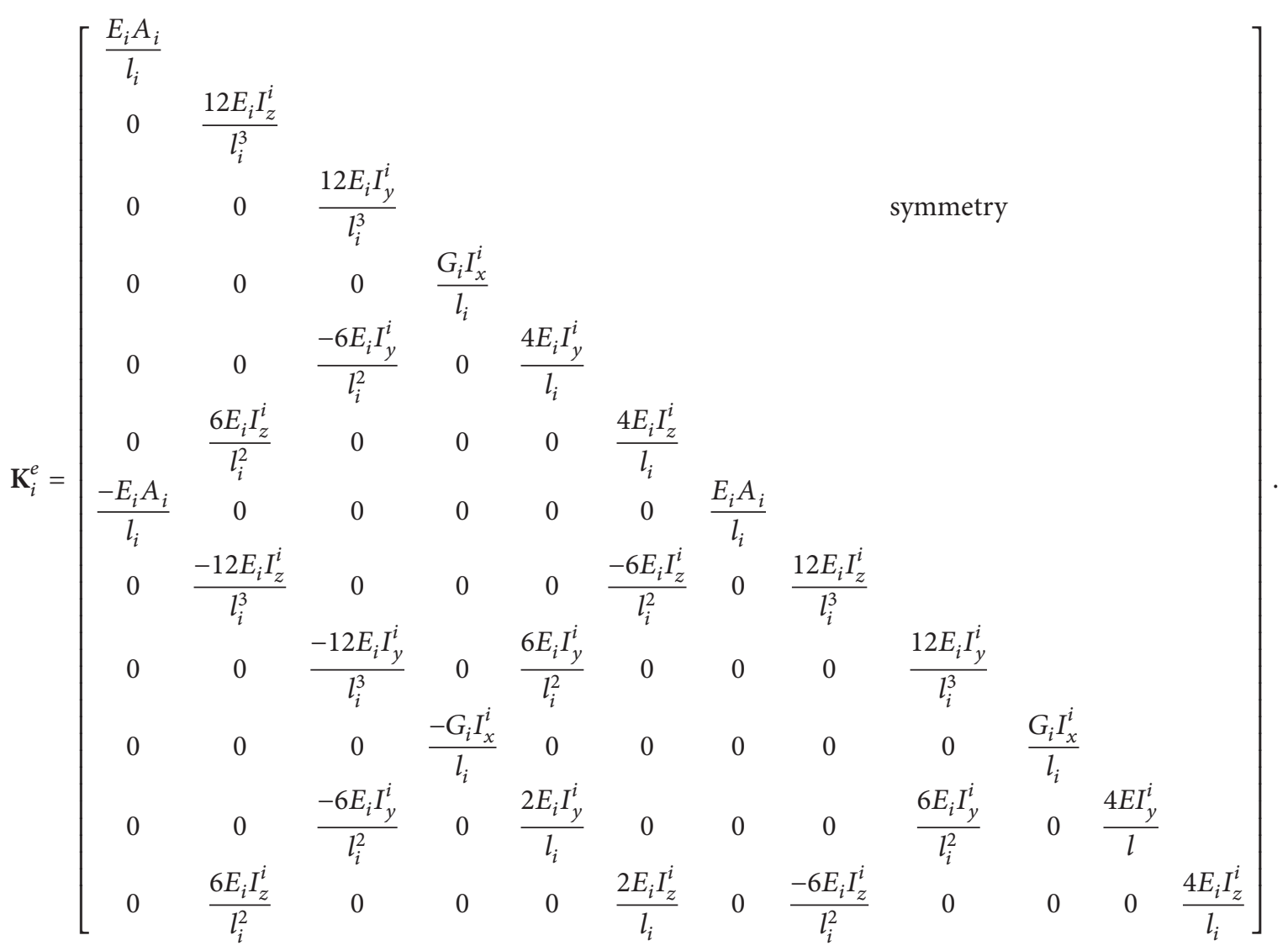


The element stiffness matrix in the global coordinate system (GCS) $\mathbf{K}_{i}$ can be expressed as the multiple of the element stiffness matrix $\mathbf{K}_{i}^{e}$ in the LCS with the coordinate transformation matrix $\mathbf{T}_{i}^{e}$

$$
\mathbf{K}_{i}=\mathbf{T}_{i}^{e T} \mathbf{K}_{i}^{e} \mathbf{T}_{i}^{e} .
$$

The mass matrix of the $i$ th element of a transmission tower in the LCS $\mathbf{M}_{i}^{e}$ can be constructed based on lumped mass assumption [20]:

$$
\mathbf{M}_{i}^{e}=\frac{\rho_{i} A_{i} l_{i}}{2} \mathbf{m}_{I}=\frac{\rho_{i} A_{i} l_{i}}{2}\left[\begin{array}{cc}
\mathbf{I}_{m} & \mathbf{0} \\
\mathbf{0} & \mathbf{I}_{m}
\end{array}\right]
$$

where

$$
\mathbf{I}_{m}=\left[\begin{array}{llllll}
1 & 0 & 0 & 0 & 0 & 0 \\
0 & 1 & 0 & 0 & 0 & 0 \\
0 & 0 & 1 & 0 & 0 & 0 \\
0 & 0 & 0 & 0 & 0 & 0 \\
0 & 0 & 0 & 0 & 0 & 0 \\
0 & 0 & 0 & 0 & 0 & 0
\end{array}\right] .
$$

The element mass matrix of the $i$ th structural member in the GCS $\mathbf{M}_{i}$ can be expressed as

$$
\mathbf{M}_{i}=\mathbf{T}_{i}^{e T} \mathbf{M}_{i}^{e} \mathbf{T}_{i}^{e} .
$$

The global mass matrix $\mathbf{M}$ and stiffness matrix $\mathbf{K}$ of the transmission tower can be expressed, respectively, as follows:

$$
\begin{aligned}
& \mathbf{M}=\sum_{i=1}^{n e} \mathbf{T}_{i}^{T} \mathbf{M}_{i}^{e} \mathbf{T}_{i}, \\
& \mathbf{K}=\sum_{i=1}^{n e} \mathbf{T}_{i}^{T} \mathbf{K}_{i}^{e} \mathbf{T}_{i},
\end{aligned}
$$

where $n e$ is the number of elements of a transmission tower; $\mathbf{T}_{i}$ is the freedom transform matrix from the LCS to the GCS.

\section{Frequency Sensitivity Analysis}

3.1. Differential Sensitivity Analysis. The performance assessment of complex structures to satisfy the dynamic responses restrictions is commonly hampered by the computational cost of dynamic analysis. There is a fundamental requirement for the information relating changes in the dynamic response quantities to changes in the structural parameters as well as a need for rapid reanalysis in structural performance evaluation. The sensitivity analysis of dynamic characteristics on structural parameters is very important and widely accepted in the structural design, optimization, and evaluation. Sensitivity coefficients are defined as the rate of change of a particular response quantity $R$ with respect to a change in a structural parameter $x$. Sensitivity coefficients can be either evaluated as absolute, relative, or normalized relative values. Relative values are independent of the units of the parameter value while, in addition, normalized relative parameters are also normalized with respect to the response value.
A differential sensitivity coefficient is the slope of the response $R_{j}$ with respect to parameter $x_{i}$, computed at a given state of the parameter. When this differential is computed for all selected responses with respect to the selected parameters, the element of the sensitivity matrix $\mathbf{S}$ is obtained:

$$
S_{j i}=\frac{\partial R_{j}}{\partial x_{i}} \quad(j=1,2, \ldots, n ; i=1,2, \ldots, m) .
$$

In which $n$ is the number of the responses; $m$ is the number of the structural parameter. The absolute sensitivity coefficient $S_{j i}$ is the $(j, i)$ th element in the sensitivity matrix $\mathbf{S}$.

The absolute sensitivity coefficients are computed by using the units of the response and parameter value. If sensitivities for different types of parameters are to be compared, the relative sensitivities can be adopted:

$$
\mathbf{S}^{r}=\mathbf{S} \cdot \mathbf{P},
$$

where $\mathbf{P}$ is a diagonal, square matrix holding the parameter values. The relative sensitivity coefficient is given by

$$
S_{j i}^{r}=\frac{\partial R_{j}}{\partial x_{i}} x_{i} \quad(j=1,2, \ldots, n ; i=1,2, \ldots, m) .
$$

Relative sensitivities can be normalized with respect to the response value

$$
\mathbf{S}^{n}=\mathbf{S}^{r} \cdot \mathbf{R}=\mathbf{S} \cdot \mathbf{P} \cdot \mathbf{R},
$$

where $\mathbf{R}$ is a diagonal, square matrix holding the response values. The normalized relative sensitivity coefficient is given by

$$
S_{j i}^{n}=R_{j}^{-1} \frac{\partial R_{j}}{\partial x_{i}} x_{i} \quad(j=1,2, \ldots, n ; i=1,2, \ldots, m) .
$$

3.2. Frequency Sensitivity. The eigenvalue equation of a MDOF transmission tower can be expressed as $[21,22]$

$$
\left(\mathbf{K}-\omega^{2} \mathbf{M}\right) \boldsymbol{\varphi}=0,
$$

where $\mathbf{M}, \mathbf{K}$, and $\varphi$ are the mass matrix, stiffness matrix and modal vector of the transmission tower respectively. The eigenvalue equation of the $r$ th mode vibration is

$$
\left(\mathbf{K}-\omega_{r}^{2} \mathbf{M}\right) \boldsymbol{\varphi}_{r}=0 .
$$

The mass matrix, stiffness matrix, and modal vector are the function of physical parameters. Thus, the first derivative of (13) to the parametric $x_{i}$ of the $i$ th structural member for the $r$ th mode vibration results in

$$
\left(\frac{\partial \mathbf{K}}{\partial x_{i}}-\frac{\partial \omega_{r}^{2}}{\partial x_{i}} \mathbf{M}-\omega_{r}^{2} \frac{\partial \mathbf{M}}{\partial x_{i}}\right) \boldsymbol{\varphi}_{r}+\left(\mathbf{K}-\omega_{r}^{2} \mathbf{M}\right) \frac{\partial \boldsymbol{\varphi}_{r}}{\partial x_{i}}=0,
$$

in which $\omega_{r}$ and $\varphi_{r}$ are the $r$ th circular frequency and modal vector of the system. Since the mass and stiffness matrices are a symmetric matrix, there exists

$$
\boldsymbol{\varphi}_{r}^{T}\left(\mathbf{K}-\omega_{r}^{2} \mathbf{M}\right)=\left[\left(\mathbf{K}-\omega_{r}^{2} \mathbf{M}\right) \boldsymbol{\varphi}_{r}\right]^{T}=0 .
$$


To pre-multiply the vector $\varphi_{r}^{T}$ to (14) will yield

$$
\frac{\partial \omega_{r}^{2}}{\partial x_{i}}=\frac{\boldsymbol{\varphi}_{r}^{T} \partial \mathbf{K} / \partial x_{i}-\omega_{r}^{2}\left(\partial \mathbf{M} / \partial x_{i}\right) \boldsymbol{\varphi}_{r}}{\boldsymbol{\varphi}_{r}^{T} \mathbf{M} \boldsymbol{\varphi}_{r}} .
$$

The relationship between the circular frequency $\omega_{r}$ and natural frequency $f_{r}$ of the $r$ th vibration mode can be written as

$$
\begin{gathered}
\frac{\partial \omega_{r}^{2}}{\partial x_{i}}=2 \omega_{r} \frac{\partial \omega_{r}}{\partial x_{i}} \\
\frac{\partial \omega_{r}}{\partial x_{i}}=2 \pi \frac{\partial f_{r}}{\partial x_{i}} .
\end{gathered}
$$

The sensitivity of the frequency to the $i$ th structural parameter $x_{i}$ is

$$
\frac{\partial f_{r}}{\partial x_{i}}=\frac{1}{8 \pi^{2} f_{r}} \cdot \frac{\boldsymbol{\varphi}_{r}^{T} \partial \mathbf{K} / \partial x_{i}-4 \pi^{2} f_{r}^{2}\left(\partial \mathbf{M} / \partial x_{i}\right) \boldsymbol{\varphi}_{r}}{\boldsymbol{\varphi}_{r}^{T} \mathbf{M} \boldsymbol{\varphi}_{r}} .
$$

Equation (18) provides a way to calculate the sensitivity of the $r$ th natural frequency to the change in the $i$ th structural parameter $x_{i}$. Assuming that the transmission tower is linear and the change in natural frequency due to the change of structural parameter is small, the change in the $r$ th natural frequency $\Delta f_{r}$, due to the variations of the structural parameter $\Delta x_{i}$, can be expressed as

$$
\Delta f_{r}=\frac{\partial f_{r}}{\partial x_{i}} \Delta x_{i}
$$

3.3. Frequency Sensitivity of Structural Parameter. The sensitivity of the $r$ th natural frequency to the structural parameter $x_{i}$ can be rewritten by using the element stiffness matrix $\mathbf{K}_{i}^{e}$ and mass matrix $\mathbf{M}_{i}^{e}$ of the $i$ th element in the GCS:

$$
\begin{aligned}
\frac{\partial f_{r}}{\partial x_{i}}= & \frac{1}{8 \pi^{2} f_{r}} \\
& \cdot \frac{\boldsymbol{\varphi}_{r}^{T} \sum_{i=1}^{n e}\left(\partial \mathbf{K}_{i}^{e} / \partial x_{i}\right)-4 \pi^{2} f_{r}^{2} \sum_{i=1}^{n e}\left(\partial \mathbf{M}_{i}^{e} / \partial x_{i}\right) \boldsymbol{\varphi}_{r}}{\boldsymbol{\varphi}_{r}^{T} \mathbf{M} \boldsymbol{\varphi}_{r}}
\end{aligned}
$$

in which ne denotes the total number of the members of the transmission tower. The sensitivity of the $r$ th natural frequency to the Young's modulus of the ith structural element $E_{i}$ is given by

$$
\frac{\partial f_{r}}{\partial E_{i}}=\frac{1}{8 \pi^{2} f_{r}} \cdot \frac{\boldsymbol{\varphi}_{r}^{T} \sum_{i=1}^{n e}\left(\partial \mathbf{K}_{i}^{e} / \partial E_{i}\right) \boldsymbol{\varphi}_{r}}{\boldsymbol{\varphi}_{r}^{T} \mathbf{M} \boldsymbol{\varphi}_{r}},
$$

where

$$
\begin{aligned}
\frac{\partial \mathbf{K}_{i}^{e}}{\partial E_{i}}= & \frac{\partial \mathbf{K}_{i}^{e}}{\partial\left(E_{i} A_{i}\right)} \cdot \frac{\partial\left(E_{i} A_{i}\right)}{\partial E_{i}}+\frac{\partial \mathbf{K}_{i}^{e}}{\partial\left(E_{i} I_{z}^{i}\right)} \cdot \frac{\partial\left(E_{i} I_{z}^{i}\right)}{\partial E_{i}} \\
& +\frac{\partial \mathbf{K}_{i}^{e}}{\partial E_{i} I_{y}^{i}} \cdot \frac{\partial E_{i} I_{y}^{i}}{\partial E_{i}}+\frac{\partial \mathbf{K}_{i}^{e}}{\partial G_{i}} \cdot \frac{\partial G_{i}}{\partial E_{i}} .
\end{aligned}
$$

The sensitivity of the $r$ th natural frequency to the density of the $i$ th structural element $\rho_{i}$ is

$$
\frac{\partial f_{r}}{\partial \rho_{i}}=-\frac{f_{r}}{2} \cdot \frac{\boldsymbol{\varphi}_{r}^{T} \sum_{i=1}^{n e}\left(\partial \mathbf{M}_{i}^{e} / \partial \rho_{i}\right) \boldsymbol{\varphi}_{r}}{\boldsymbol{\varphi}_{r}^{T} \mathbf{M} \boldsymbol{\varphi}_{r}} .
$$

Substituting (3) into (23) yields

$$
\frac{\partial f_{r}}{\partial \rho_{i}}=-\frac{f_{r} \sum_{i=1}^{n e} A_{i} l_{i}}{4} \cdot \frac{\boldsymbol{\varphi}_{r}^{T} \mathbf{m}_{I} \boldsymbol{\varphi}_{r}}{\boldsymbol{\varphi}_{r}^{T} \mathbf{M} \boldsymbol{\varphi}_{r}}
$$

where $A_{i}$ and $L_{i}$ are the cross area and the length of the $i$ th element, respectively. The sensitivity of the $r$ th natural frequency to the cross area of the $i$ th structural element $A_{i}$ is

$$
\begin{aligned}
\frac{\partial f_{r}}{\partial A_{i}}= & \frac{1}{8 \pi^{2} f_{r}} \\
& \cdot \frac{\boldsymbol{\varphi}_{r}^{T} \sum_{i=1}^{n e}\left(\partial \mathbf{K}_{i}^{e} / \partial A_{i}\right)-4 \pi^{2} f_{r}^{2} \sum_{i=1}^{n e}\left(\partial \mathbf{M}_{i}^{e} / \partial A_{i}\right) \boldsymbol{\varphi}_{r}}{\boldsymbol{\varphi}_{r}^{T} \mathbf{M} \boldsymbol{\varphi}_{r}}
\end{aligned}
$$

where

$$
\begin{gathered}
\frac{\partial \mathbf{M}_{i}^{e}}{\partial A_{i}}=\frac{\rho_{i} l_{i}}{2} \mathbf{m}_{I}, \\
\frac{\partial \mathbf{K}_{i}^{e}}{\partial A_{i}}=\frac{E_{i}}{l_{i}} \mathbf{A}_{I}=\frac{E_{i}}{l_{i}}\left[\begin{array}{cc}
\mathbf{I}_{A} & -\mathbf{I}_{A} \\
-\mathbf{I}_{A} & \mathbf{I}_{A}
\end{array}\right], \\
\mathbf{I}_{A}=\left[\begin{array}{llllll}
1 & 0 & 0 & 0 & 0 & 0 \\
0 & 0 & 0 & 0 & 0 & 0 \\
0 & 0 & 0 & 0 & 0 & 0 \\
0 & 0 & 0 & 0 & 0 & 0 \\
0 & 0 & 0 & 0 & 0 & 0 \\
0 & 0 & 0 & 0 & 0 & 0
\end{array}\right] .
\end{gathered}
$$

The sensitivity of the $r$ th natural frequency to the moment of inertia $I_{x}^{i}, I_{y}^{i}$, and $I_{z}^{i}$ of the $i$ th structural element can be expressed as

$$
\begin{aligned}
& \frac{\partial f_{r}}{\partial I_{x}^{i}}=\frac{1}{8 \pi^{2} f_{r}} \cdot \frac{\boldsymbol{\varphi}_{r}^{T} \sum_{i=1}^{n e}\left(\partial \mathbf{K}_{i}^{e} / \partial I_{x}^{i}\right) \boldsymbol{\varphi}_{r}}{\boldsymbol{\varphi}_{r}^{T} \mathbf{M} \boldsymbol{\varphi}_{r}}, \\
& \frac{\partial f_{r}}{\partial I_{y}^{i}}=\frac{1}{8 \pi^{2} f_{r}} \cdot \frac{\boldsymbol{\varphi}_{r}^{T} \sum_{i=1}^{n e}\left(\partial \mathbf{K}_{i}^{e} / \partial I_{y}^{i}\right) \boldsymbol{\varphi}_{r}}{\boldsymbol{\varphi}_{r}^{T} \mathbf{M} \boldsymbol{\varphi}_{r}} \\
& \frac{\partial f_{r}}{\partial I_{z}^{i}}=\frac{1}{8 \pi^{2} f_{r}} \cdot \frac{\boldsymbol{\varphi}_{r}^{T} \sum_{i=1}^{n e}\left(\partial \mathbf{K}_{i}^{e} / \partial I_{z}^{i}\right) \boldsymbol{\varphi}_{r}}{\boldsymbol{\varphi}_{r}^{T} \mathbf{M} \boldsymbol{\varphi}_{r}} .
\end{aligned}
$$

The sensitivity of the $r$ th natural frequency to the Poisson's ratio of the $i$ th structural element $\mu_{i}$ is

$$
\frac{\partial f_{r}}{\partial \mu_{i}}=\frac{1}{8 \pi^{2} f_{r}} \cdot \frac{\boldsymbol{\varphi}_{r}^{T} \sum_{i=1}^{n e}\left(\partial \mathbf{K}_{i}^{e} / \partial \mu_{i}\right) \boldsymbol{\varphi}_{r}}{\boldsymbol{\varphi}_{r}^{T} \mathbf{M} \boldsymbol{\varphi}_{r}},
$$

where

$$
\frac{\partial \mathbf{K}_{i}^{e}}{\partial \mu_{i}}=-\frac{I_{x}^{i}}{1+\mu_{i}} \cdot \frac{\partial \mathbf{K}_{i}^{e}}{\partial I_{x}^{i}}
$$




\section{Case Study}

4.1. Description of an Example Transmission Tower. To examine the frequency sensitivity based on the proposed approach, a real transmission tower constructed in China is taken as the example structure. Figure 1 shows the elevation of a large transmission tower used for electric power transfer. The transmission tower with a height of $84.5 \mathrm{~m}$ is located in the southern coastal area in China. The structural members used in the transmission tower are made of Q235 steel with a yielding stress of $235 \mathrm{MPa}$. Young's modulus of the steel is $2.01 \times 10^{11} \mathrm{~N} / \mathrm{m}^{2}$ and the density is $7800 \mathrm{~kg} / \mathrm{m}^{3}$. The vertical major members, the skew members, the cross arms, and the platform of the tower are formed as a spatial truss tower as shown in Figures 2(a), 2(b), and 2(c), respectively. Six platforms are connected to the vertical major members to form the tower body and the skew members are incorporated to increase the vertical and lateral stiffness of the entire tower. Two cross arms are constructed on top of the tower body for the connection of the transmission lines. A threedimensional FE model is constructed based on the FE method with the aids of the commercial package.

A three-dimensional finite element model is established for the steel transmission tower using a commercial computer package. The model has a total of $13243 \mathrm{D}$ beam elements and 488 nodes with 6 degrees of freedom at each node. All the joints in the finite element model are assumed to be rigid. The movement of all the supports in the three orthogonal directions is restricted. For the sake of convenience in the subsequent discussion, the beam elements in each component of the transmission tower are numbered differently. The beam elements in the vertical major members are numbered from 1 to 80 (denote $\mathrm{zc}$ ), the elements in the platforms are numbered from 81 to 408 (denote pt), the elements in the skew members are counted from 409 to 772 (denote $\mathrm{xg}$ ), the elements in the lower cross arm are counted from 773 to 1072 (denote hd1), and the elements in the upper cross arm are counted from 1073 to 1324 (denote hd2). The number of vertical major members is only $6 \%$ of the total number of elements used in the structure while the number of skew members is $24.7 \%$ of the total number of elements used in the structure. Except that the vertical major members are of hollow circular section, all the other members are of angle section.

4.2. Dynamic Characteristics of the Transmission Tower. The dynamic characteristics analysis is conducted based on the established finite element model of the steel transmission tower. The first eight natural frequencies and vibration modes of the tower are depicted in Table 1 and Figure 3, respectively. The first natural frequencies of the transmission tower for the out-of-plane and in-plane vibration are $1.736 \mathrm{~Hz}$ and $1.759 \mathrm{~Hz}$, respectively. It is seen that the first and second vibration modes are the global vibration mode in the $x$ direction and $y$ direction, respectively. The third vibration mode is a global torsional vibration mode in the $x-y$ plane due to the tower rotation. The fourth to sixth vibration modes are the high order translational and torsional vibration modes of the tower. The first eight natural frequencies computed
TABLE 1: Dynamic properties of the transmission tower.

\begin{tabular}{|c|c|c|}
\hline Number & $\begin{array}{l}\text { Natural } \\
\text { frequency } \\
(\mathrm{Hz})\end{array}$ & Properties of the mode shape \\
\hline$f_{1}$ & 1.736 & $\begin{array}{l}\text { 1st global vibration mode in the } x \\
\text { direction }\end{array}$ \\
\hline$f_{2}$ & 1.759 & $\begin{array}{l}\text { 1st global vibration mode in the } y \\
\text { direction }\end{array}$ \\
\hline$f_{3}$ & 2.63 & 1st global torsional vibration mode \\
\hline$f_{4}$ & 3.541 & $\begin{array}{l}\text { 2nd global vibration mode in the } x \\
\text { direction }\end{array}$ \\
\hline$f_{5}$ & 3.961 & $\begin{array}{l}\text { 2nd global vibration mode in the } y \\
\text { direction }\end{array}$ \\
\hline$f_{6}$ & 4.26 & 2nd global torsional vibration mode \\
\hline$f_{7}$ & 4.849 & $\begin{array}{l}\text { Local vibration mode of the } \\
\text { platform }\end{array}$ \\
\hline$f_{8}$ & 5.767 & $\begin{array}{l}\text { 3rd global vibration mode in the } x \\
\text { direction }\end{array}$ \\
\hline
\end{tabular}

indicate that the natural frequencies of the structure are not closely spaced. The dynamic responses of the first three mode shapes are the major parts of the entire dynamic responses of the transmission tower.

4.3. Frequency Sensitivity of the Transmission Tower. Figure 4 shows the sensitivities of the first eight natural frequencies to Young's modulus of each member. It is seen from the first two figures that the first two natural frequencies are more sensitive to Young's modulus change of members in the vertical major members ( $\mathrm{zc}$ ) than other members. The curves in the third figure indicate that the sensitivity coefficients of the first torsional frequency of the skew members are much larger than those of the other members. All the higher natural frequencies of the global vibration are more sensitive to Young's modulus change of both vertical major members and the skew members. This is consistent with the structural configuration and the modes of vibration; the first two translational modes of vibration are mainly due to the deformation of the vertical major members and the first torsional mode is due to the deformation of the skew members. However, the higher modes of vibration are mainly due to the movement combination of both vertical major members and the skew members. The seventh vibration mode is the local vibration of the platform number 1 and thereby the seventh natural frequency is clearly sensitive to Young's modulus of the platform number 1. To compare the magnitude of the sensitivity coefficients in Figure 4, one can find that Young's modulus of the vertical major members plays an important role in the first two vibration modes in comparison with all the other vibration modes. The sensitivity coefficients of the skew members are slightly smaller than those of the vertical major members.

Displayed in Figure 5 is the sensitivity of the first eight natural frequencies to the density of the material. It is well known that the natural frequencies decrease with 


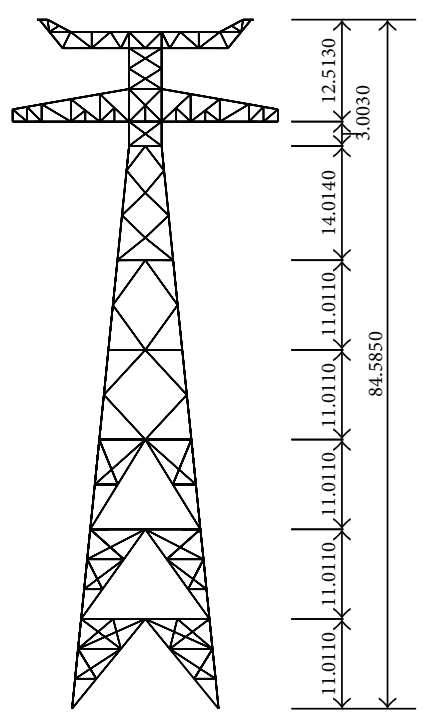

(a) Elevation

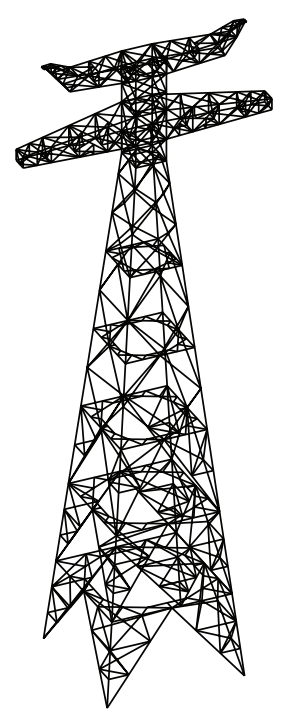

(b) 3D model

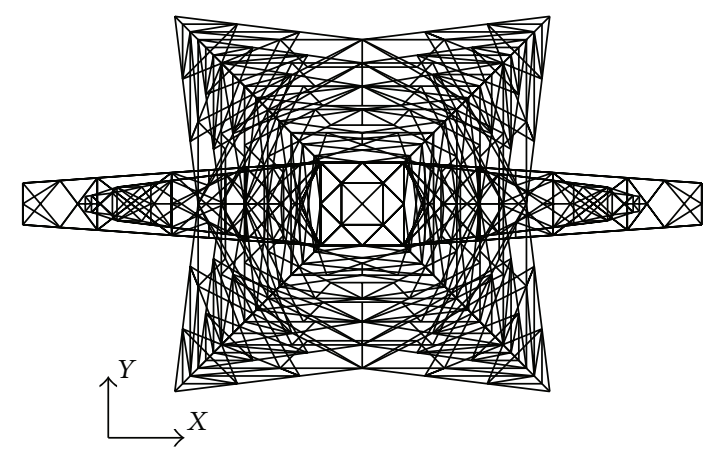

(c) Plane view

FIgURE 1: Analytical model of the example transmission tower.

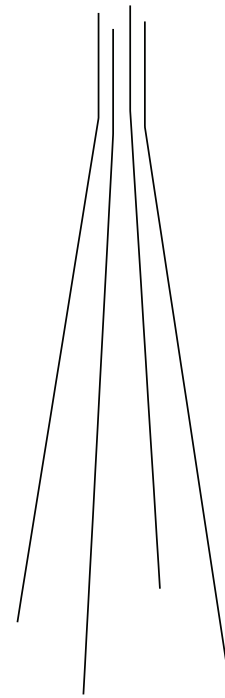

(a) Vertical major members $(\mathrm{zc})$

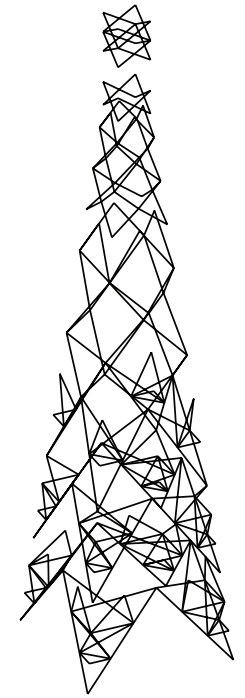

(b) Skew members (xg)

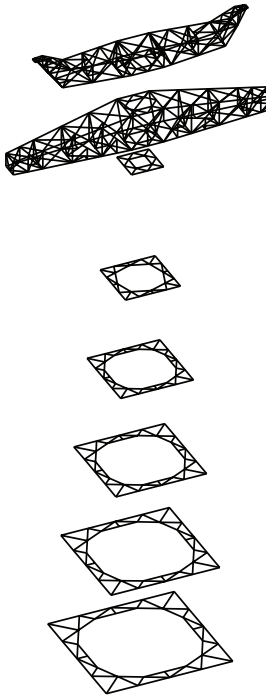

(c) Cross arm (hd) and platform (pt)

Figure 2: Configuration of the example transmission tower.

the increasing material density. Therefore, it is indicated from Figure 5 that the sensitivity coefficients are negative. It is seen that the sensitivity coefficients of the natural frequencies to the density are quite different to those of Young's modulus. The first two figures demonstrate that the first two natural frequencies are more sensitive to the density change of members in the vertical major members $(\mathrm{zc})$ and cross arms. However, the density sensitivity coefficients of the skew members and platforms are much smaller. The curves in the third figure indicate that the sensitivity coefficients of the first torsional frequency of the two cross arms are much larger than those of the other members. This is because the third mode is the torsional vibration of the two cross arms. The second-order translational frequencies of both the outof-plane vibration and in-plane vibration, namely, the fourth and fifth frequencies, are dominantly sensitive to the density change of the vertical major members. Similar observations can be made from the density sensitivity of the second order torsional modes (e.g., the sixth mode) because this mode is the torsional vibration of the tower body. Regarding 


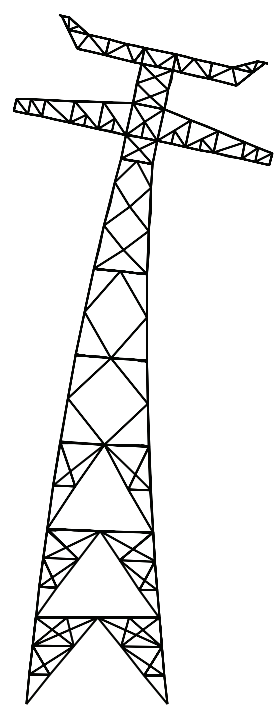

(a) 1 st

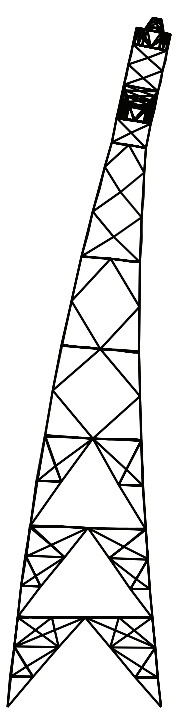

(b) 2nd

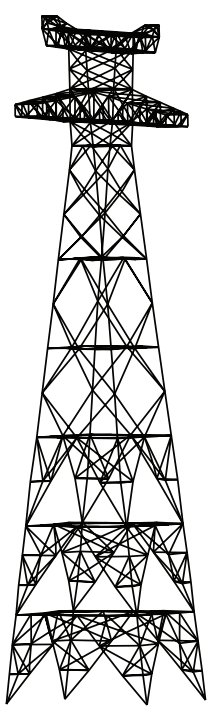

(c) $3 \mathrm{rd}$

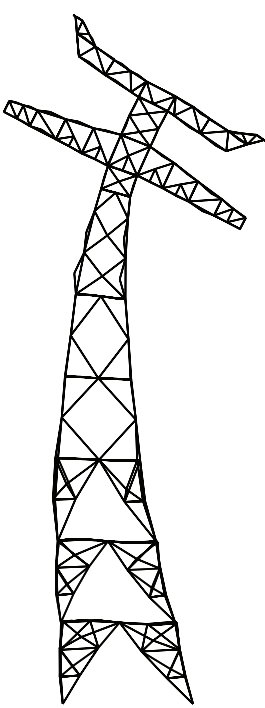

(d) 4 th

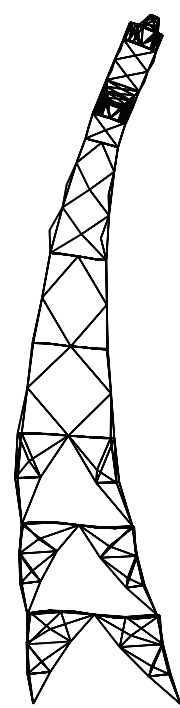

(e) 5 th

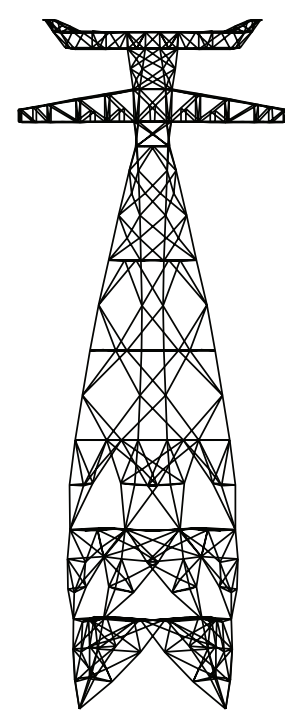

(f) 6 th

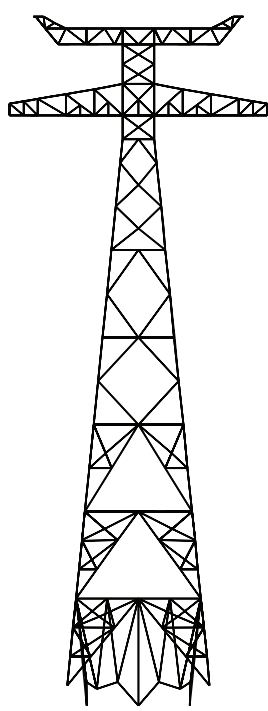

(g) 7 th

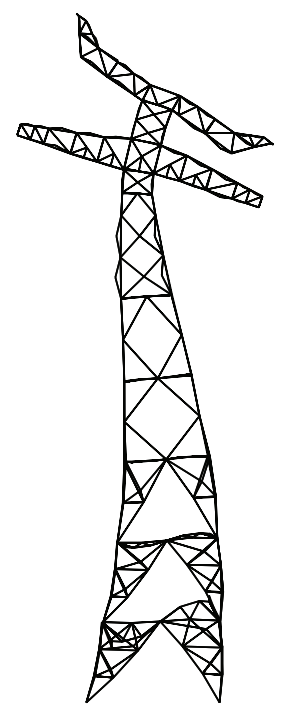

(h) 8 th

FIGURE 3: First eight mode shapes of the example transmission tower.

the higher order translational modes, the density of skew members may have slight effects on the sensitivity coefficients as shown in the eighth figures in Figure 5.

Figure 6 indicates the sensitivities of the first eight natural frequencies to the cross area of each member. It is clear that the sensitivity coefficients of the cross area are quite different to those of Young's modulus and density. The increase of member cross area does not always cause the increment of the structural natural frequencies. It is seen from the first two figures that the first two natural frequencies are more sensitive to the cross area change of the vertical major members than other members. As far as the first two natural frequencies are concerned, the increase in cross area of most of the vertical major members may induce the increment of the natural frequencies. On the contrary, the increase in the member cross areas of the two cross arms may lead to the increase of the global mass instead of the stiffness. Therefore, the structural natural frequencies may decrease to some extents. As displayed in the third figure, the skew members can be strengthened by increasing the cross areas and the third natural frequency, corresponding to the first order torsional mode, can be increased. Similar observations can be found from the sensitivity coefficients of the other higher natural frequencies. It is seen that the sensitivity coefficients of Young's modulus and the cross area are similar to great extents. The stiffness matrix of the $i$ th element of a transmission tower in the local coordinate system $\mathbf{K}_{i}^{e}$ is expressed in (1). It can be found that both Young's modulus $E$ and cross area $A$ have an important contribution to the axial stiffness $E A / l$ of a single member. In addition, Young's modulus also makes the contribution to the member bending stiffness $E I / l^{3}$. Therefore, the comparison between 


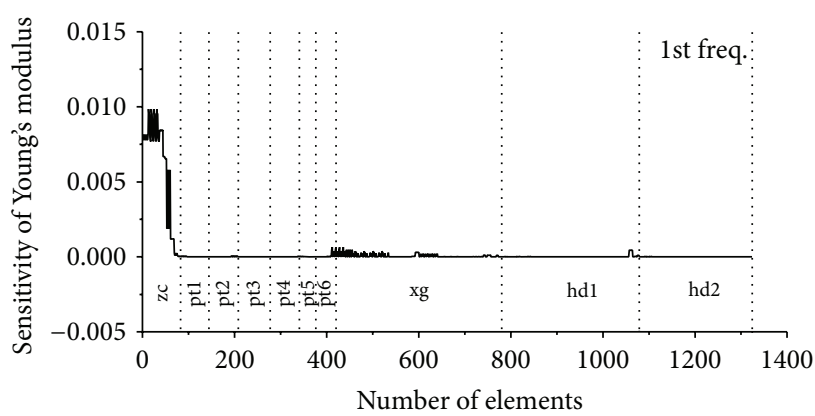

(a)

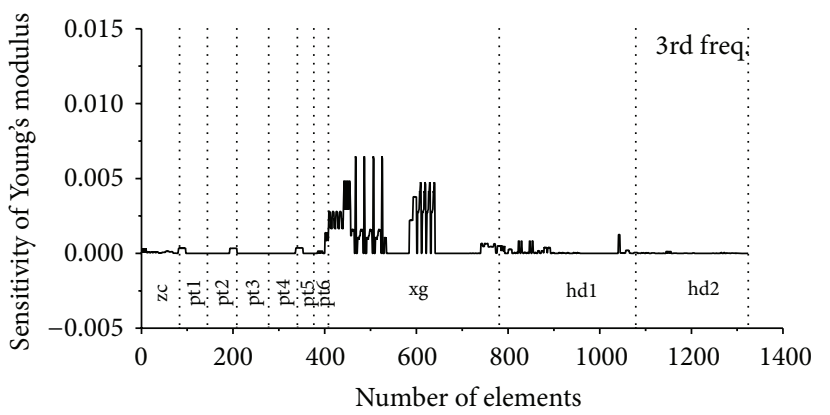

(c)

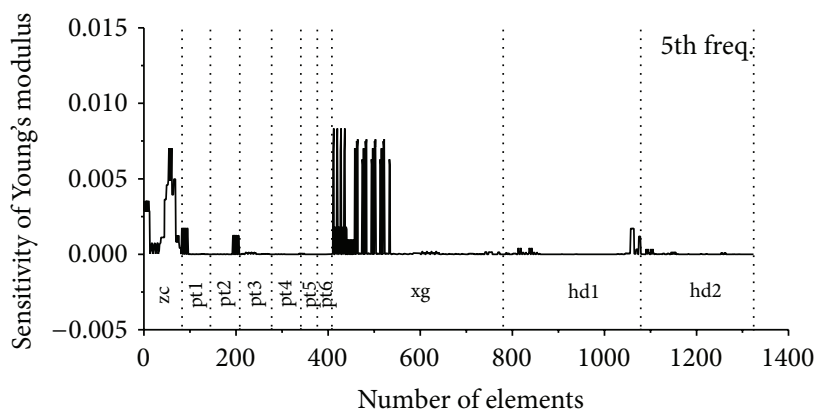

(e)

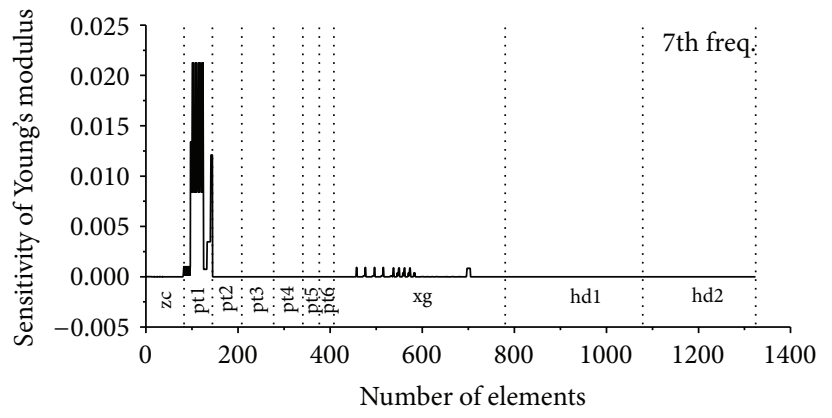

(g)

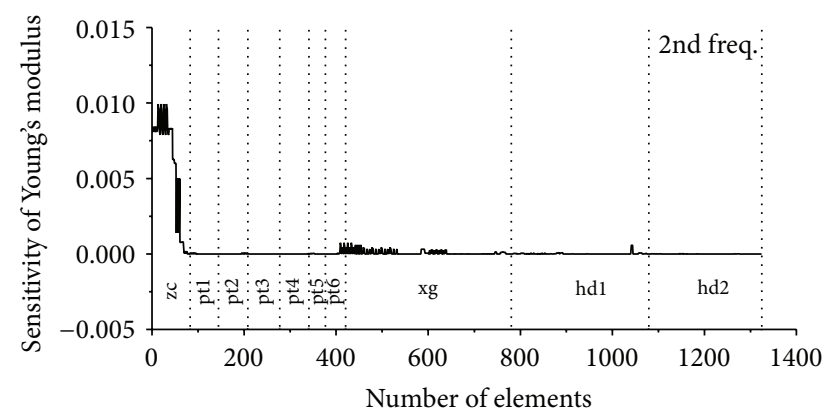

(b)

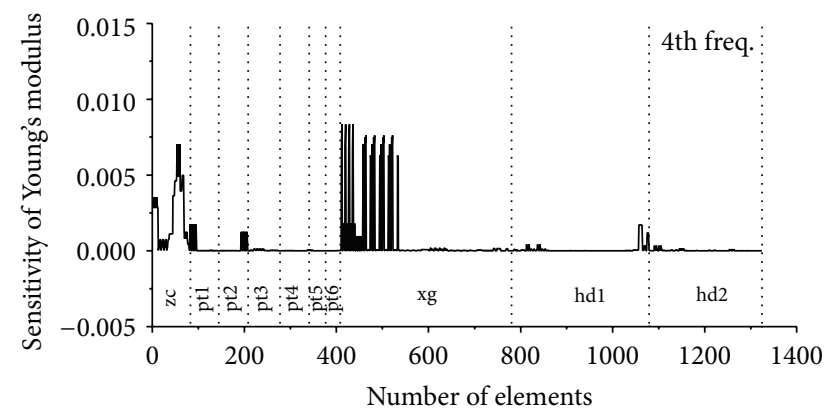

(d)

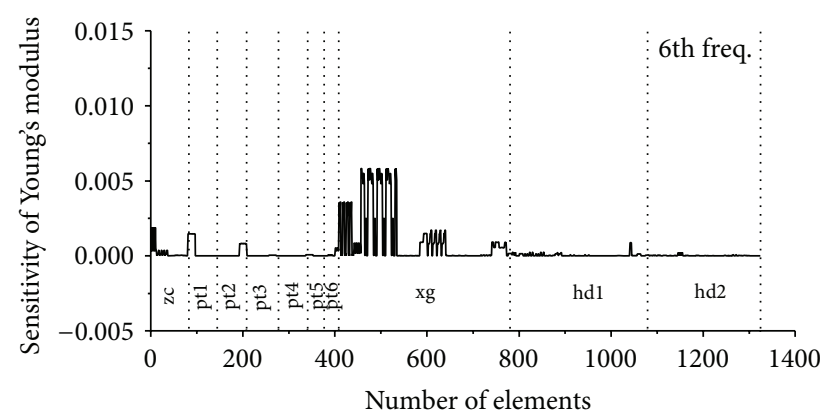

(f)

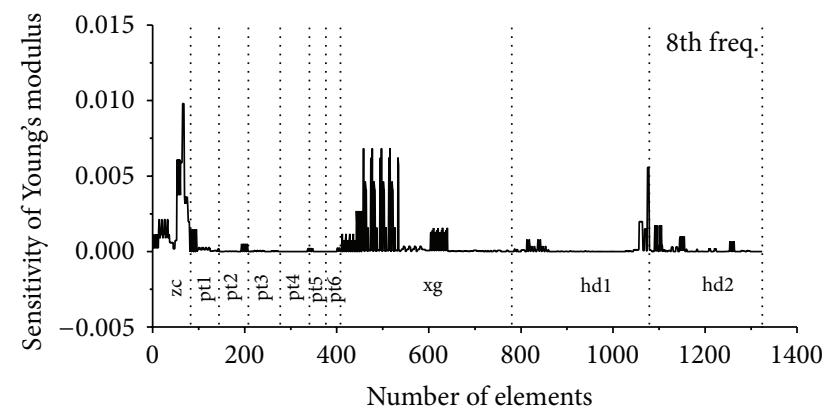

(h)

FIGURE 4: Sensitivity of first eight natural frequencies to the Young's modulus.

Figures 4 and 6 indicates that the magnitudes of the sensitivity coefficients of Young's modulus are slightly larger than those of the cross area.

Sensitivity of the first eight natural frequencies to the torsional stiffness $I_{x}$ is displayed in Figure 7. It is seen from the third figure that the sensitivity coefficients of the third frequency to the torsional stiffness are much larger than those of the all the other frequencies. Therefore, the frequency sensitivity coefficients to the torsional stiffness are substantially smaller than those of Young's modulus, the density, and the cross area. The torsional stiffness of structural members may have a certain level of effects on the torsional 


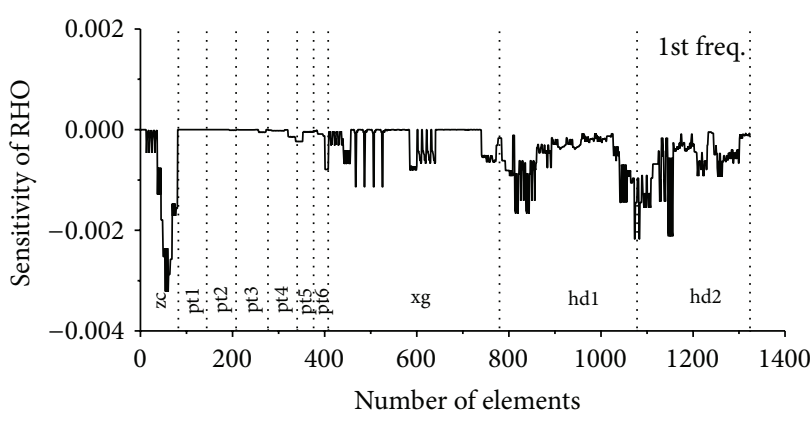

(a)

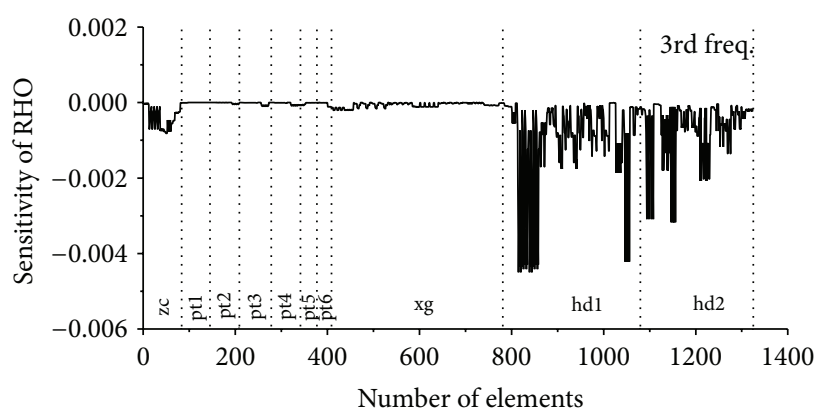

(c)

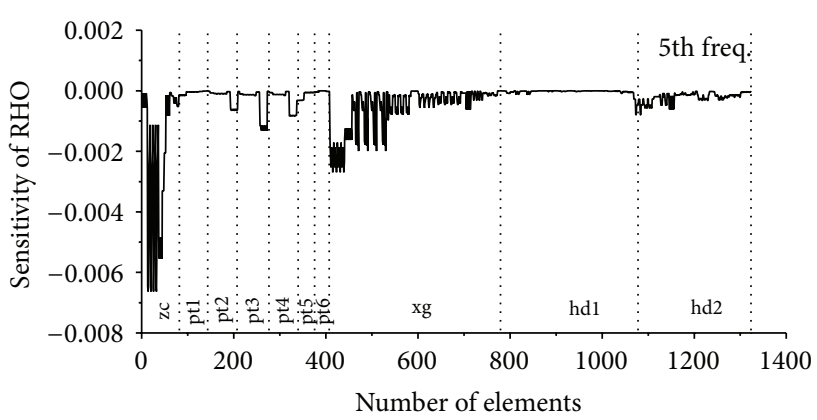

(e)

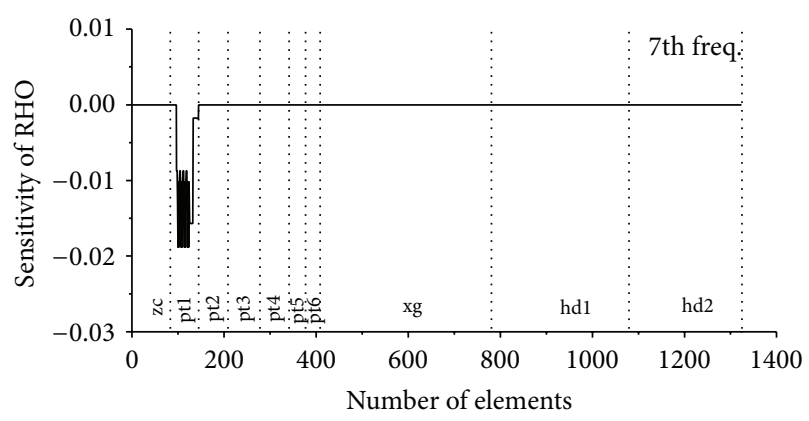

(g)

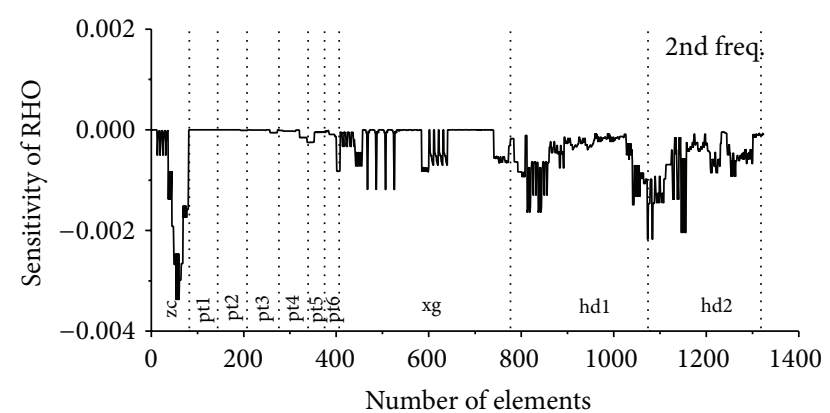

(b)

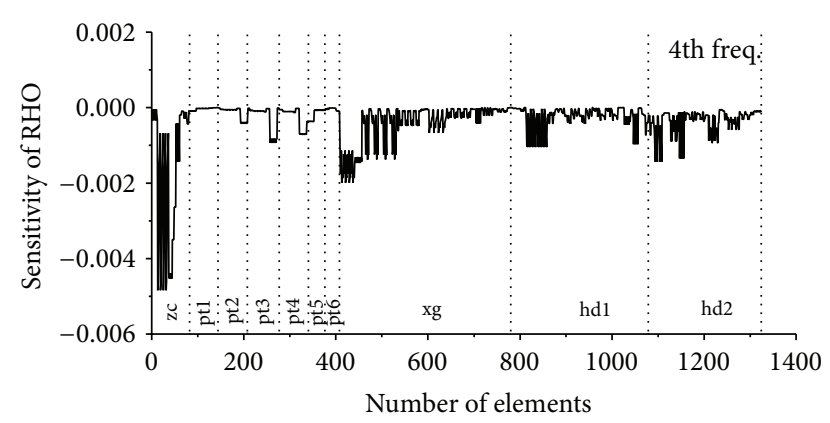

(d)

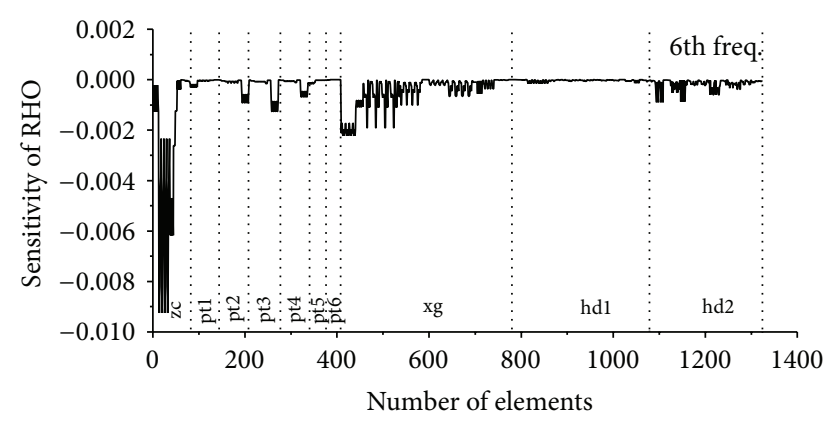

(f)

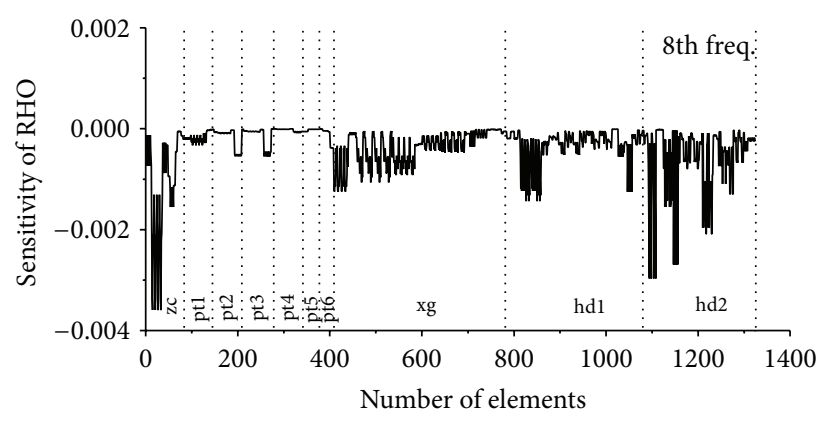

(h)

FIGURE 5: Sensitivity of first 8 natural frequencies to the density of material.

vibration modes of the transmission tower. The sensitivity of first eight natural frequencies to the bending moment of inertia $I_{y}$ and $I_{z}$ are indicated in Figures 8 and 9, respectively. Similarly, the frequency sensitivity coefficients to the bending moment stiffness are also remarkably smaller than those of
Young's modulus, the density, and the cross area. It is found that the sensitivity coefficients of the major vertical members are much larger than those of the other members for the first five natural frequencies. This observation means that the effects of the bending moment inertia of the major vertical 


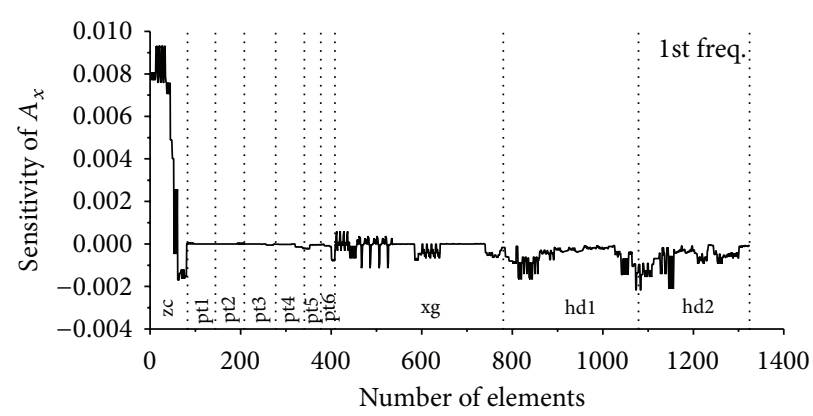

(a)

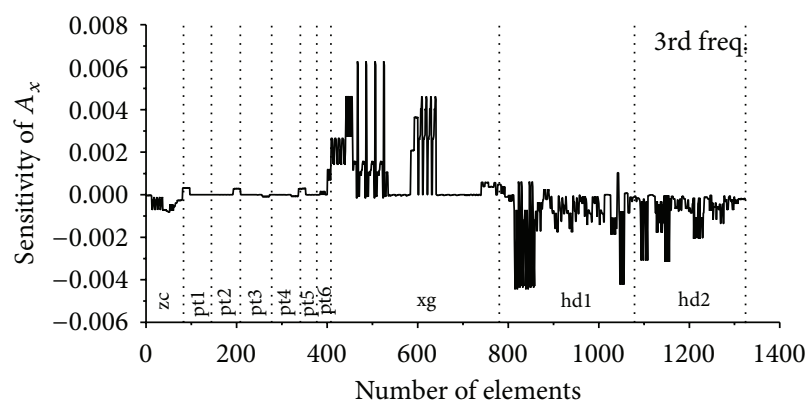

(c)

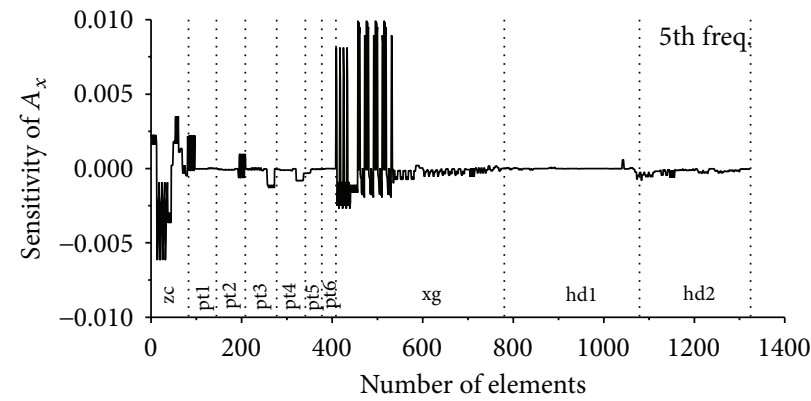

(e)

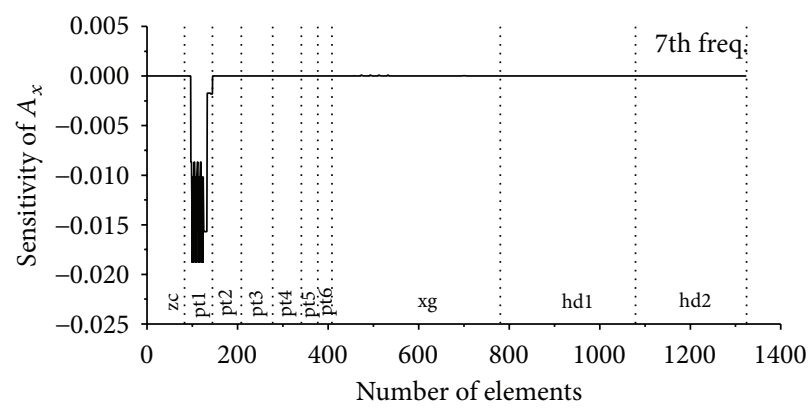

(g)

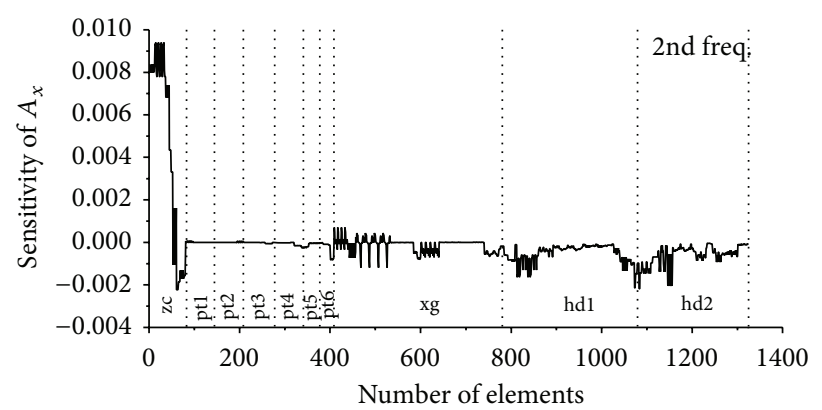

(b)

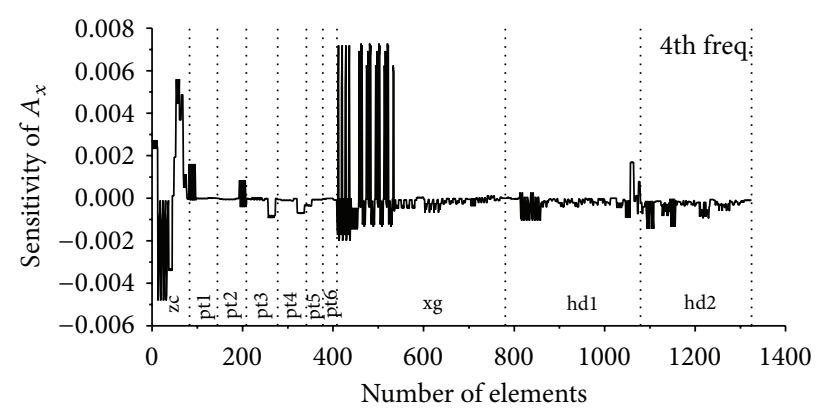

(d)

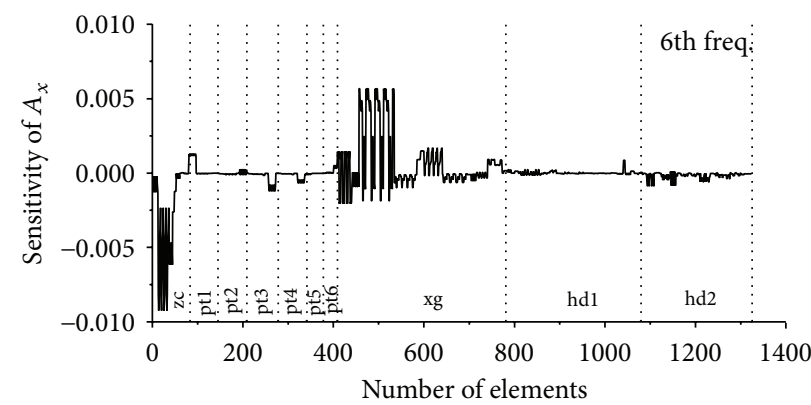

(f)

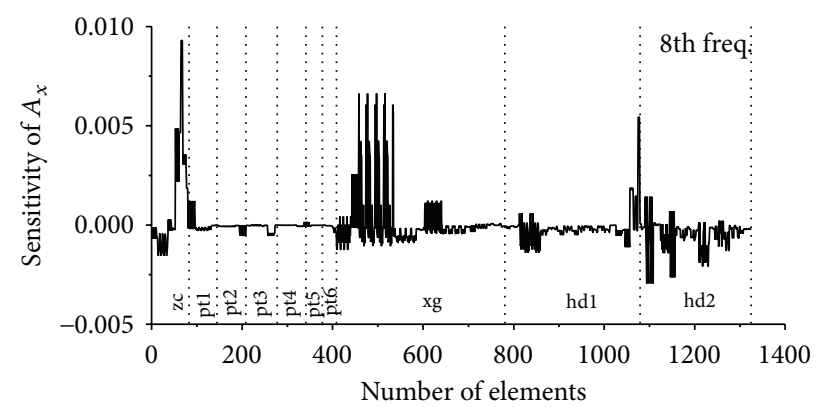

(h)

FIGURE 6: Sensitivity of first eight natural frequencies to the cross area.

members on structural modal properties are more obvious in comparison with other members.

\section{Concluding Remarks}

The feasibility of evaluating the parametric effects of a transmission tower based on the frequency sensitivity analysis is actively carried out in this study. The 3D analytical model of a transmission tower is first constructed by using the FE method. The differential sensitivity analysis approach is presented based on the differential sensitivity coefficient, the absolute sensitivity coefficient, and the relative sensitivity coefficient, respectively. The sensitivity coefficients to natural frequencies are deduced based on the equation of motion of the tower. In addition, the expression of the frequency 


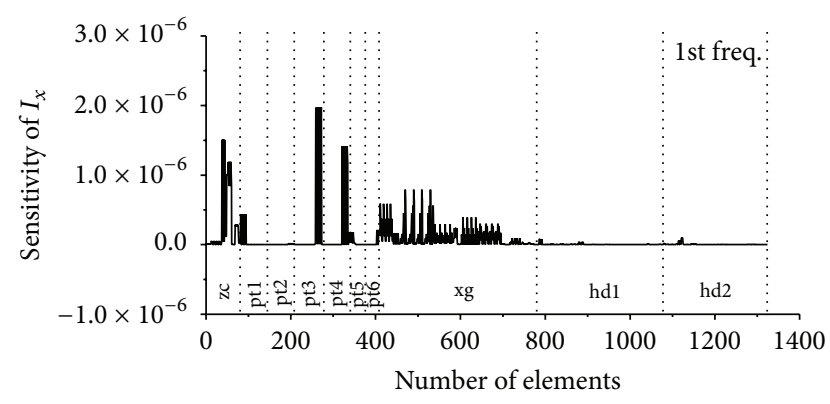

(a)

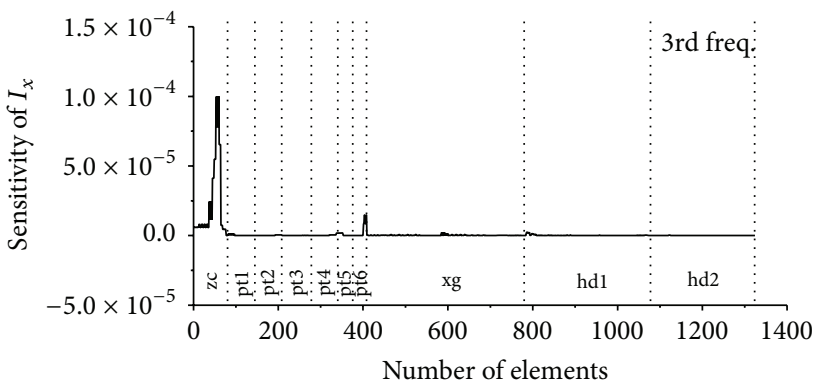

(c)

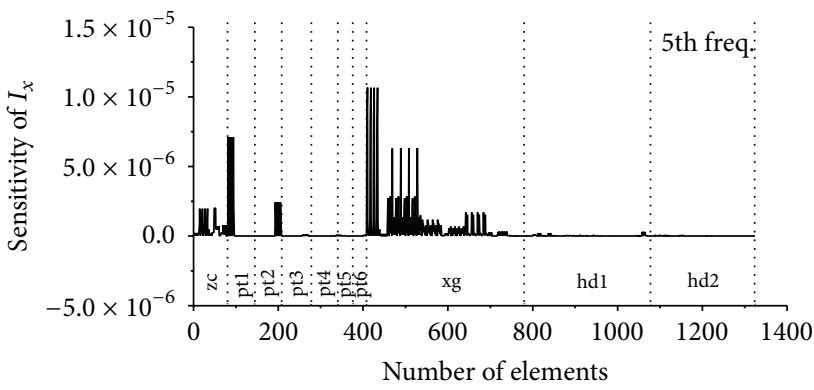

(e)

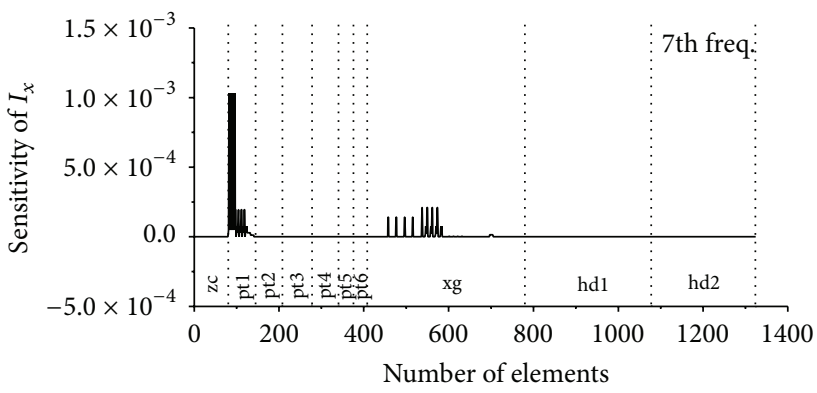

(g)

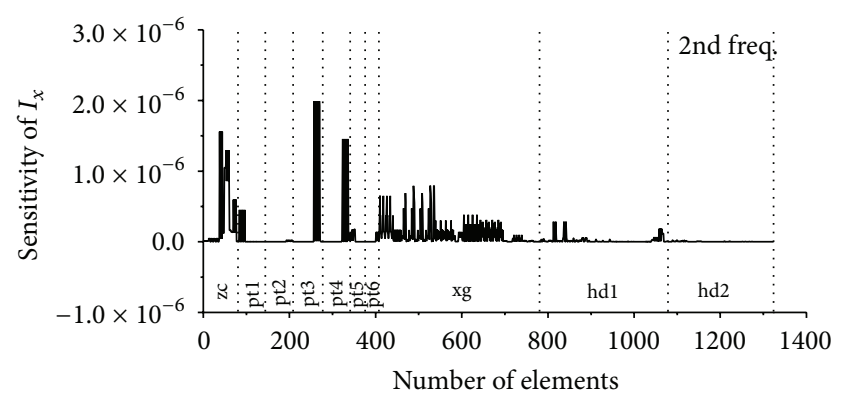

(b)

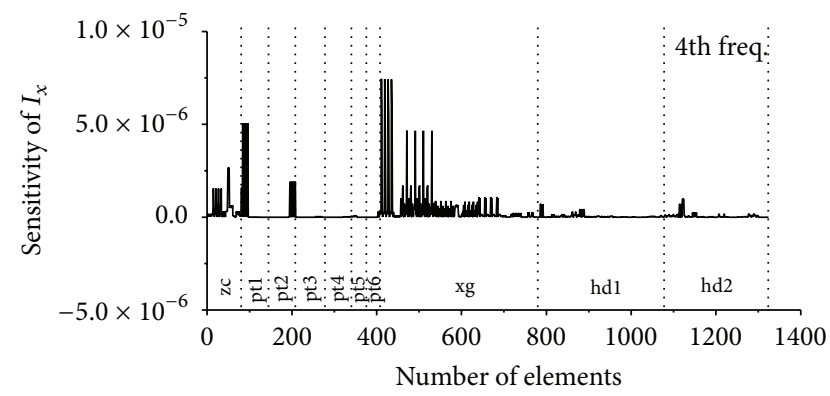

(d)

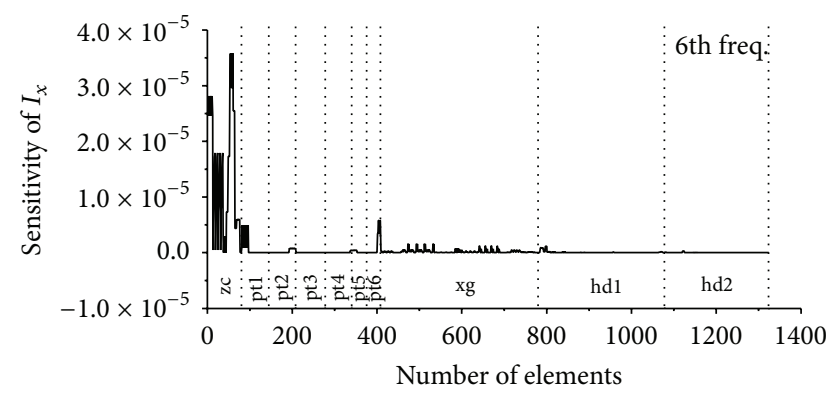

(f)

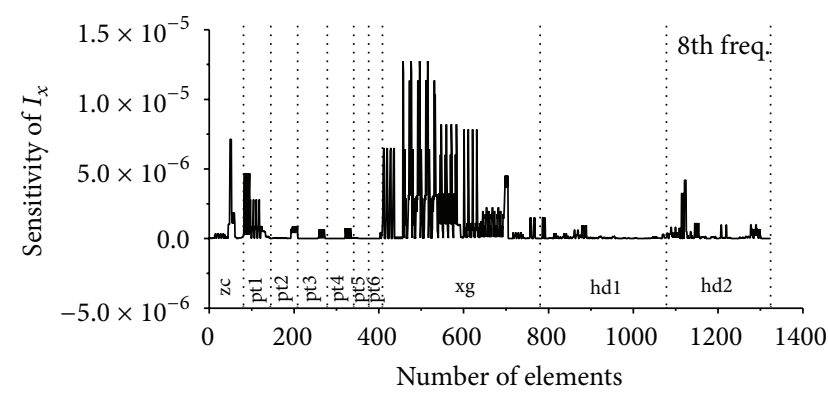

(h)

FIGURE 7: Sensitivity of first eight natural frequencies to the torsional stiffness $I_{x}$.

sensitivity to Young's modulus, density of material, the cross area of members, torsional stiffness, and bending moment inertia is proposed. A real transmission tower-line system is taken as the example to investigate the effects of the structural parameters on the natural frequency through the detailed parametric study.

The observations made demonstrate that Young's modulus of the vertical major members plays an important role in the first two vibration modes in comparison with all the other vibration modes. The sensitivity coefficients of the skew members are slightly smaller than those of the vertical major members. The sensitivity coefficients of the natural frequencies to the density are different to those of Young's modulus because the natural frequencies decrease with the increasing material density. The sensitivity coefficients of the cross area are quite different to those of Young's modulus and 


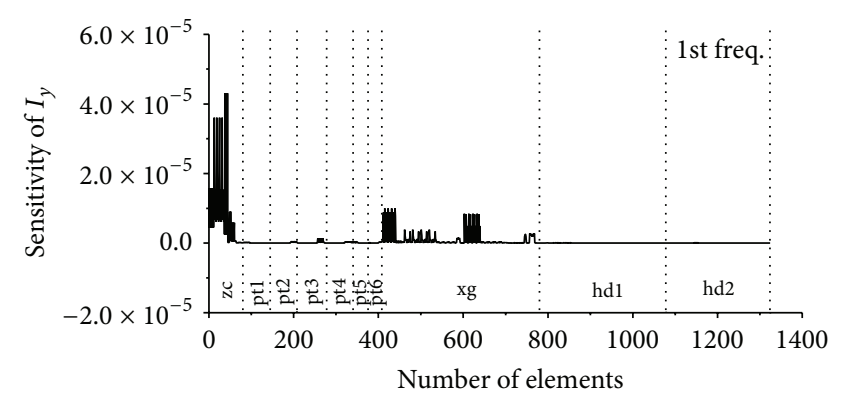

(a)

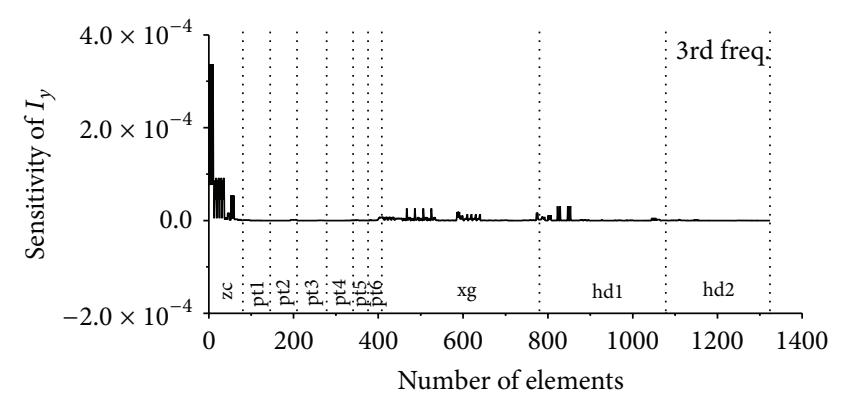

(c)

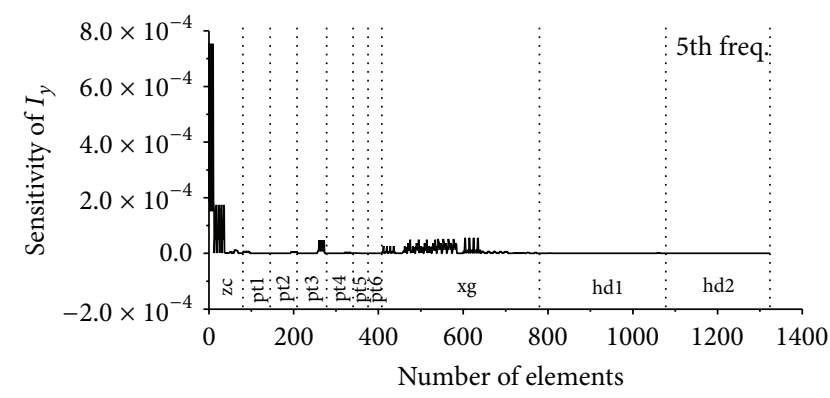

(e)

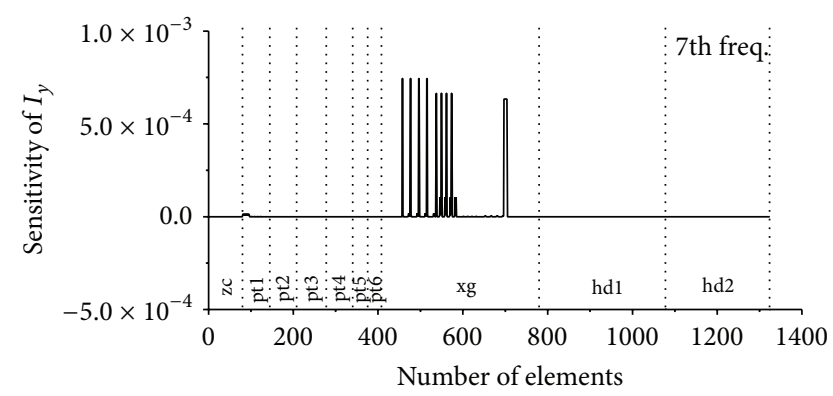

(g)

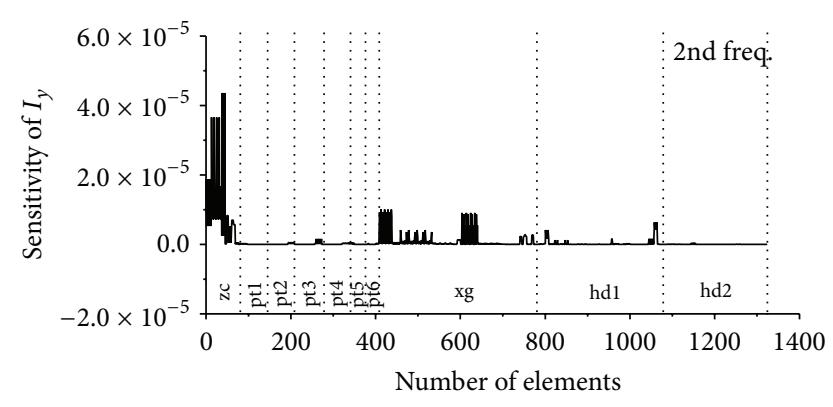

(b)

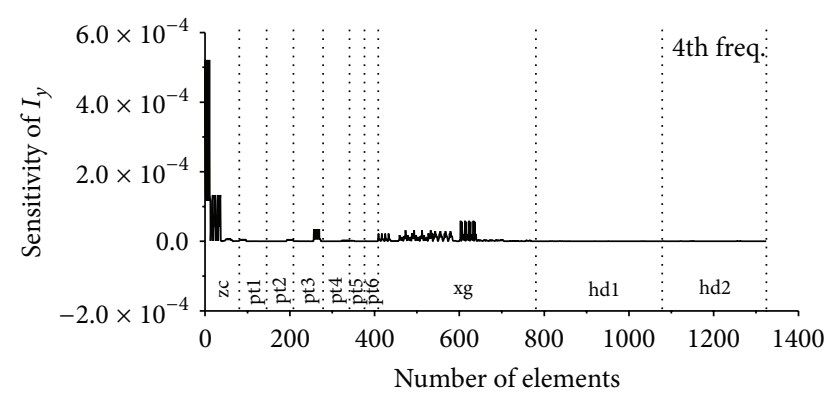

(d)

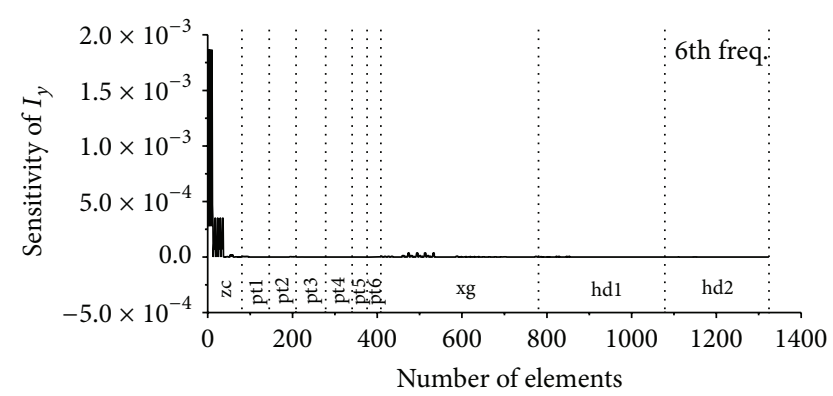

(f)

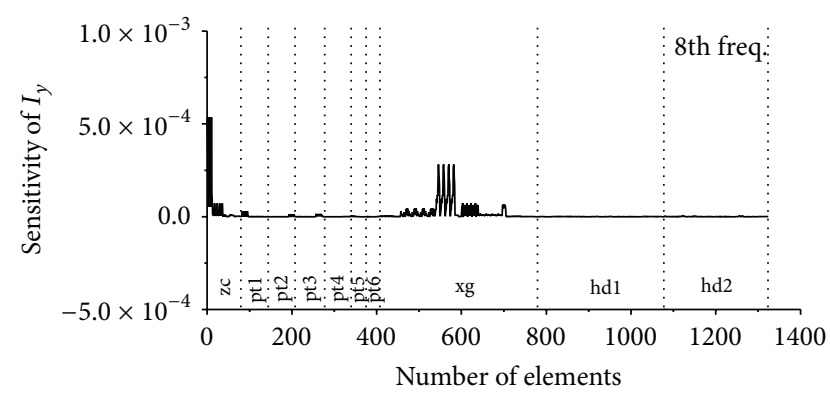

(h)

FIGURE 8: Sensitivity of first eight natural frequencies to the bending moment of inertia $I_{y}$.

density. The increase of member cross area does not always cause the increment of the structural natural frequencies. The frequency sensitivity coefficients to the torsional stiffness and the bending moment stiffness are substantially smaller than those of Young's modulus, the density, and the cross area. To compare the magnitudes of the sensitivity coefficients, one can find that Young's modulus, the density, and the cross area are more important structural parameters in assessing the dynamic performance of the transmission tower.

\section{Conflict of Interests}

The authors declare that there is no conflict of interests regarding the publication of this paper.

\section{Acknowledgments}

The writers are grateful for the financial support from the Technological Project of the Chinese Southern Power Grid 


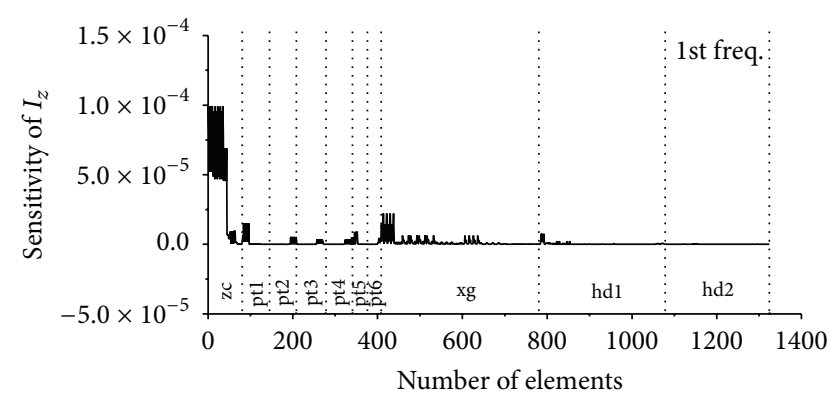

(a)

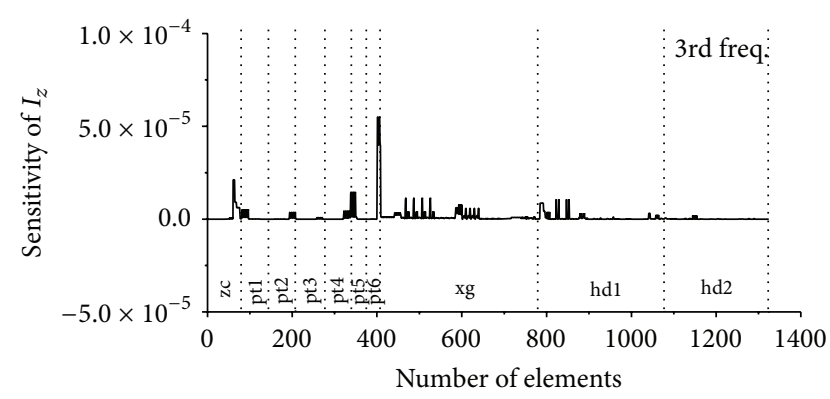

(c)

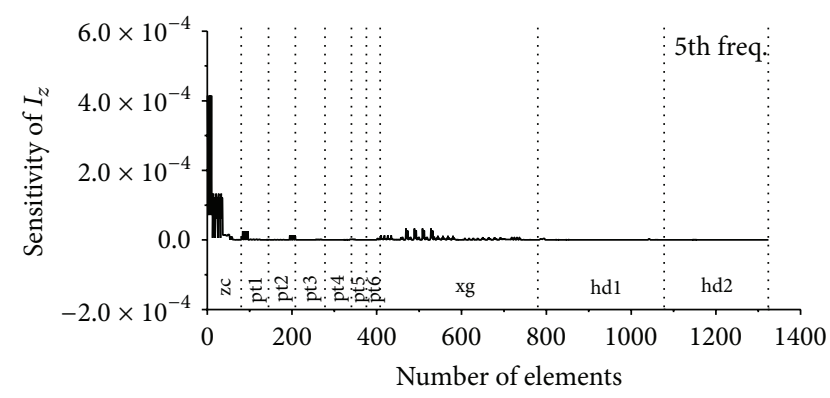

(e)

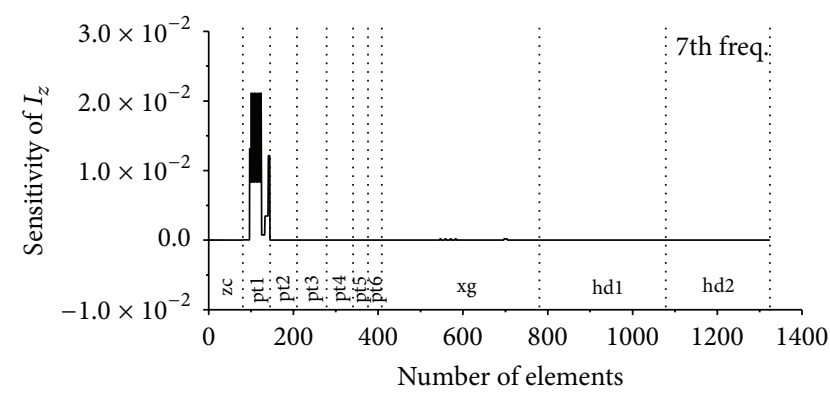

(g)

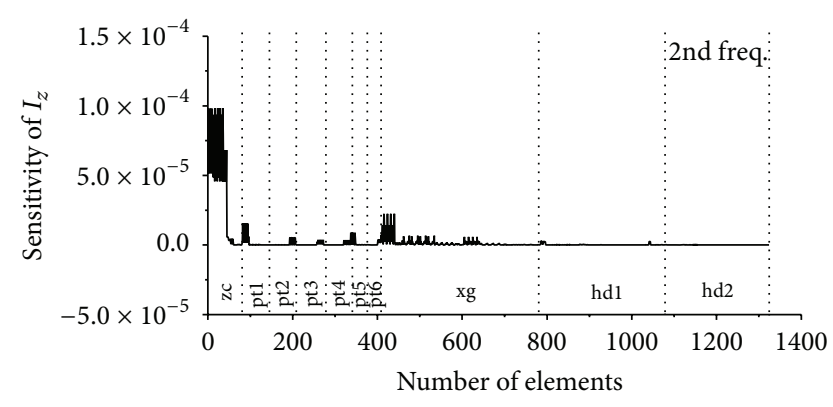

(b)

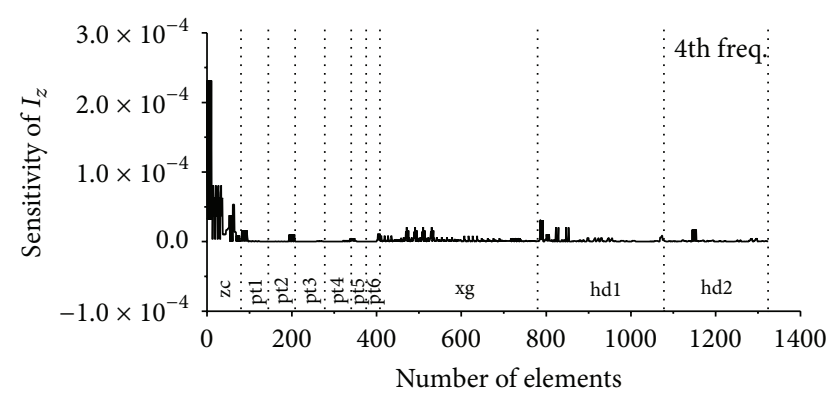

(d)

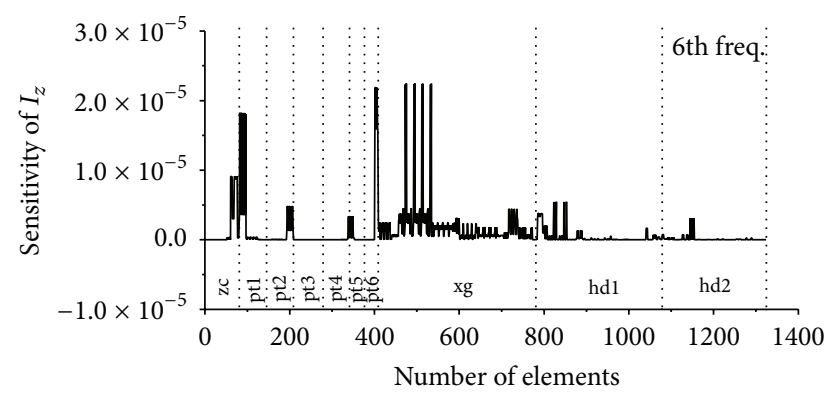

(f)

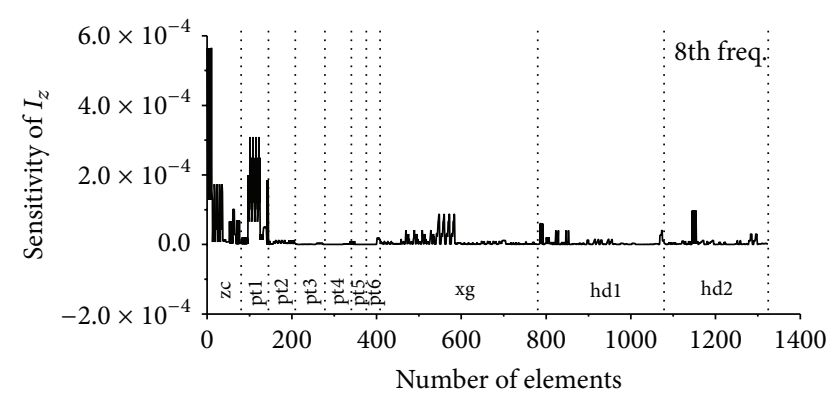

(h)

FIGURE 9: Sensitivity of first eight natural frequencies to the bending moment of inertia $I_{z}$.

Co. Ltd. (K-GD2013-0783), the Natural Science Foundation of Hubei Province (2014CFA026), and the Fok Ying-Tong Education Foundation (131072).

\section{References}

[1] E. Savory, G. A. R. Parke, M. Zeinoddini, N. Toy, and P. Disney, "Modelling of tornado and microburst-induced wind loading and failure of a lattice transmission tower," Engineering Structures, vol. 23, no. 4, pp. 365-375, 2001.

[2] B. Chen, J. Zheng, and W. L. Qu, "Control of wind-induced response of transmission tower-line system by using magnetorheological dampers," International Journal of Structural Stability and Dynamics, vol. 9, no. 4, pp. 661-685, 2009.

[3] E. Simiu and R. Scanlan, Wind Effects on Structures, John Wiley \& Sons, New York, NY, USA, 3rd edition, 1996. 
[4] Q. Xie and L. Sun, "Failure mechanism and retrofitting strategy of transmission tower structures under ice load," Journal of Constructional Steel Research, vol. 74, pp. 26-36, 2012.

[5] R. C. Battista, R. S. Rodrigues, and M. S. Pfeil, "Dynamic behavior and stability of transmission line towers under wind forces," Journal of Wind Engineering and Industrial Aerodynamics, vol. 91, no. 8, pp. 1051-1067, 2003.

[6] H. N. Li, S. Y. Tang, and T. H. Yi, "Wind-rain-induced vibration test and analytical method of high-voltage transmission tower," Structural Engineering and Mechanics, vol. 48, no. 4, pp. 435453, 2013.

[7] P.-S. Lee and G. McClure, "Elastoplastic large deformation analysis of a lattice steel tower structure and comparison with full-scale tests," Journal of Constructional Steel Research, vol. 63, no. 5, pp. 709-717, 2007.

[8] T. Okamura, T. Ohkuma, E. Hongo, and H. Okada, "Wind response analysis of a transmission tower in a mountainous area," Journal of Wind Engineering and Industrial Aerodynamics, vol. 91, no. 1-2, pp. 53-63, 2003.

[9] H. Sohn, C. R. Farrar, F. M. Hemez, D. D. Shunk, D. W. Stinemates, and B. R. Nadler, "A review of structural health monitoring literature :1996-2001," Los Alamos National Laboratory Report LA-13976-MS, 2003.

[10] B. Chen, S.-L. Zhao, and P.-Y. Li, "Application of HilbertHuang transform in structural health monitoring: a state-ofthe-art review," Mathematical Problems in Engineering, vol. 2014, Article ID 317954, 22 pages, 2014.

[11] B. Chen, Y. L. Xu, and X. Zhao, "Integrated vibration control and health monitoring of building structures: a time-domain approach," Smart Structures and Systems-An International Journal, vol. 6, no. 7, pp. 811-833, 2010.

[12] Y. Q. Ni, X. W. Ye, and J. M. Ko, "Monitoring-based fatigue reliability assessment of steel bridges: analytical model and application," Journal of Structural Engineering, vol. 136, no. 12, pp. 1563-1573, 2010.

[13] X. W. Ye, Y. H. Su, and J. P. Han, "Structural health monitoring of civil infrastructure using optical fiber sensing technology: a comprehensive review," The Scientific World Journal, vol. 2014, Article ID 652329, 11 pages, 2014.

[14] M. L. Friswell and J. E. Mottershead, Finite Element Model Updating in Structural Dynamics, Kluwer Academic, Norwell, Mass, USA, 1995.

[15] S. W. Doebling, C. R. Farrar, M. B. Prime, and D. W. Shevitz, "A review of damage identification methods that examine changes in dynamic properties," Shock and Vibration Digest, vol. 30, no. 2, pp. 91-105, 1998.

[16] B. Chen, Y. L. Xu, and W. L. Qu, "Evaluation of atmospheric corrosion damage to steel space structures in coastal areas," International Journal of Solids and Structures, vol. 42, no. 16-17, pp. 4673-4694, 2005.

[17] B. Chen and Y. L. Xu, "A new damage index for detecting sudden change of structural stiffness," International Journal of Structural Engineering and Mechanics, vol. 26, no. 3, pp. 315-341, 2007.

[18] K. J. Bathe, Finite Element Procedures, Prentice-Hall, Englewood Cliffs, NJ, USA, 1996.

[19] H. M. Irvine, Cable Structure, The MIT Press, New York, NY, USA, 1981.

[20] R. W. Clough and J. Penzien, Dynamic of Structures, McGrawHill, New York, NY, USA, 3rd edition, 2003.

[21] Y. L. Xu and B. Chen, "Integrated vibration control and health monitoring of building structures using semi-active friction dampers: part I-methodology," Engineering Structures, vol. 30, no. 7, pp. 1789-1801, 2008.

[22] B. Chen and Y. L. Xu, "Integrated vibration control and health monitoring of building structures using semi-active friction dampers: part II-numerical investigation," Engineering Structures, vol. 30, no. 3, pp. 573-587, 2008. 

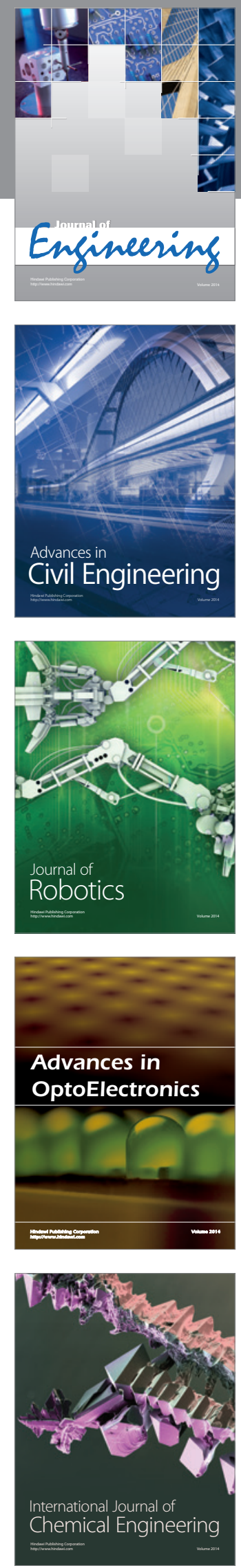

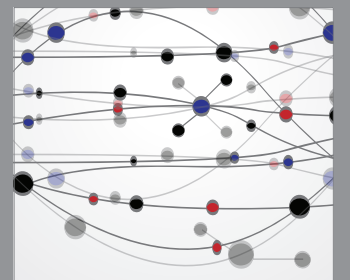

The Scientific World Journal
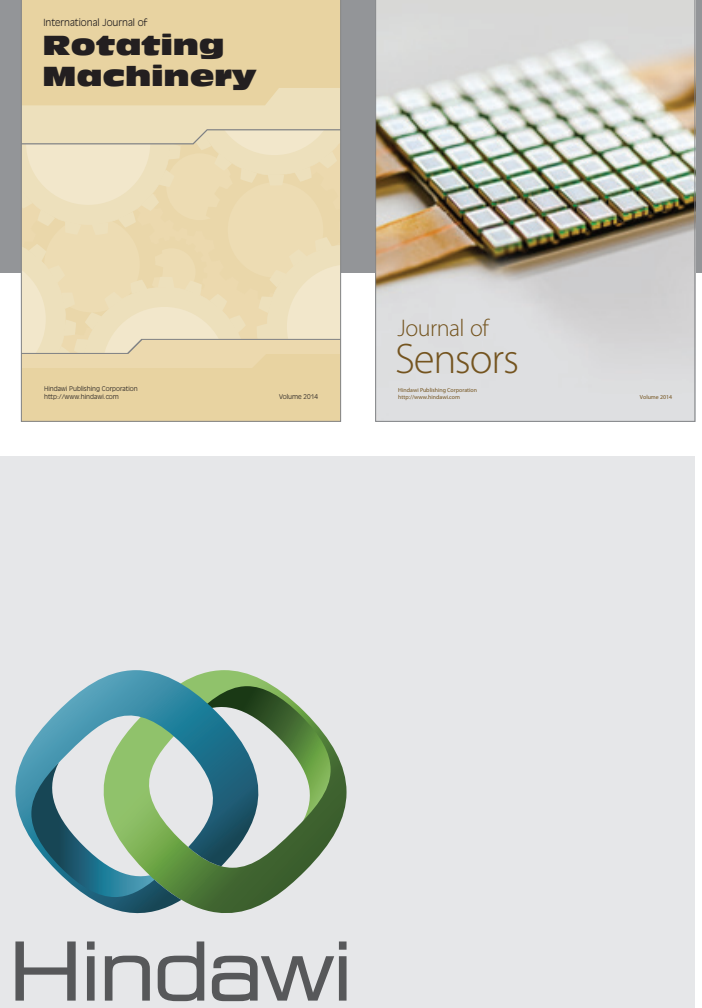

Submit your manuscripts at http://www.hindawi.com
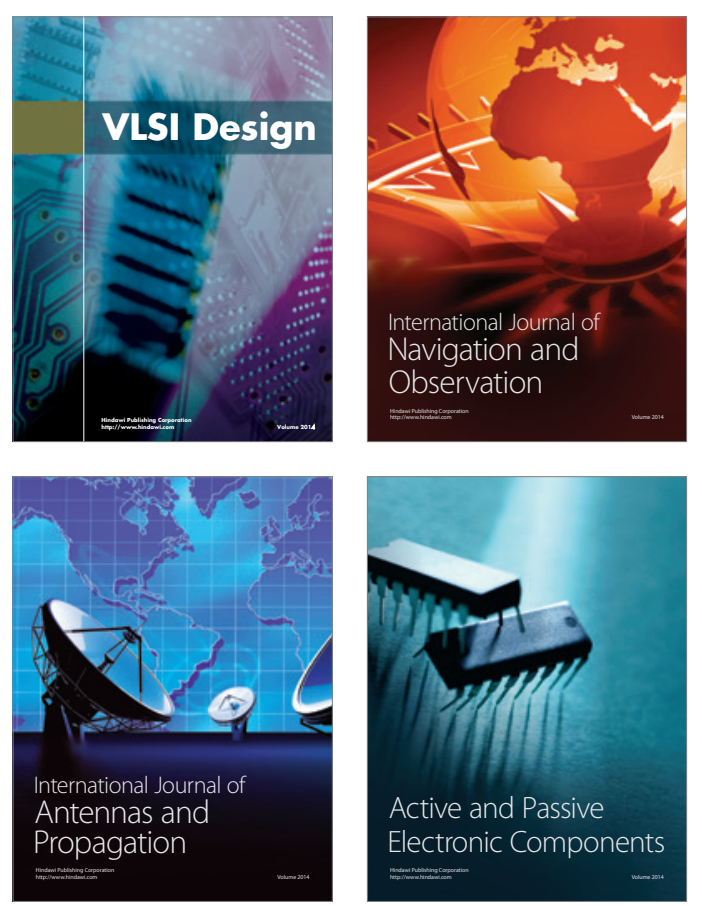
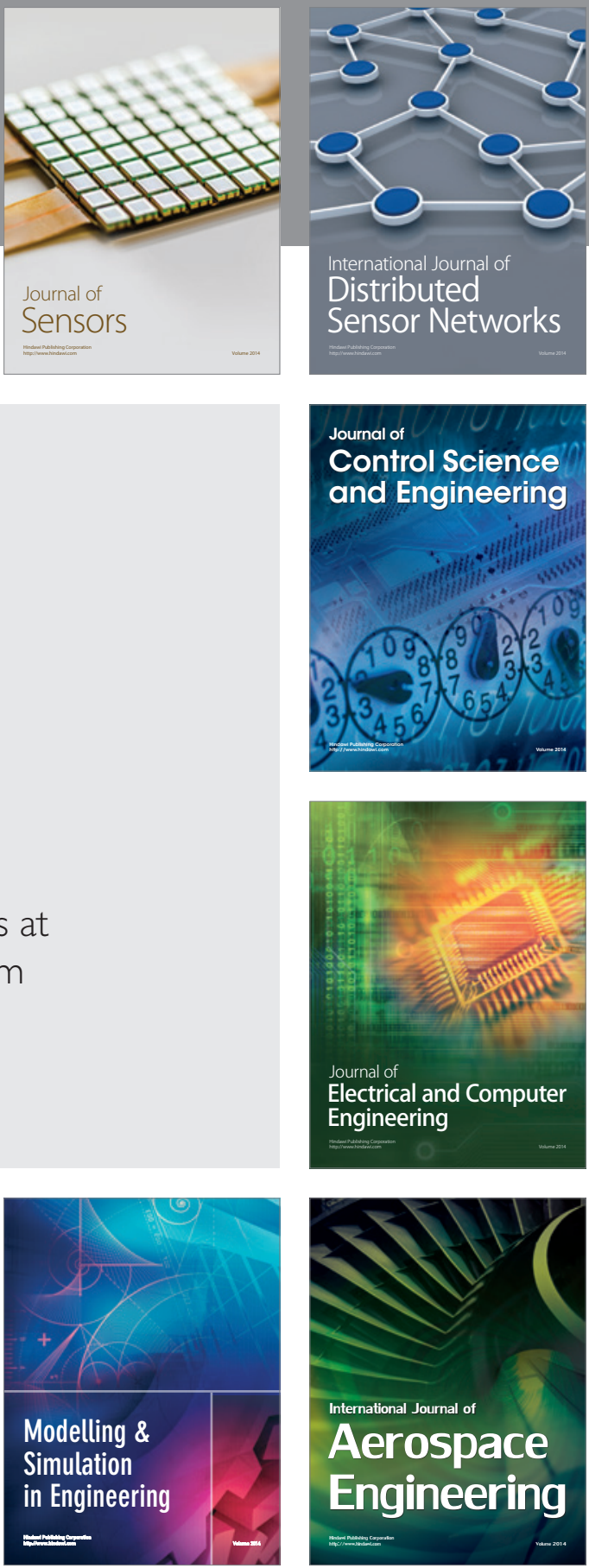

Journal of

Control Science

and Engineering
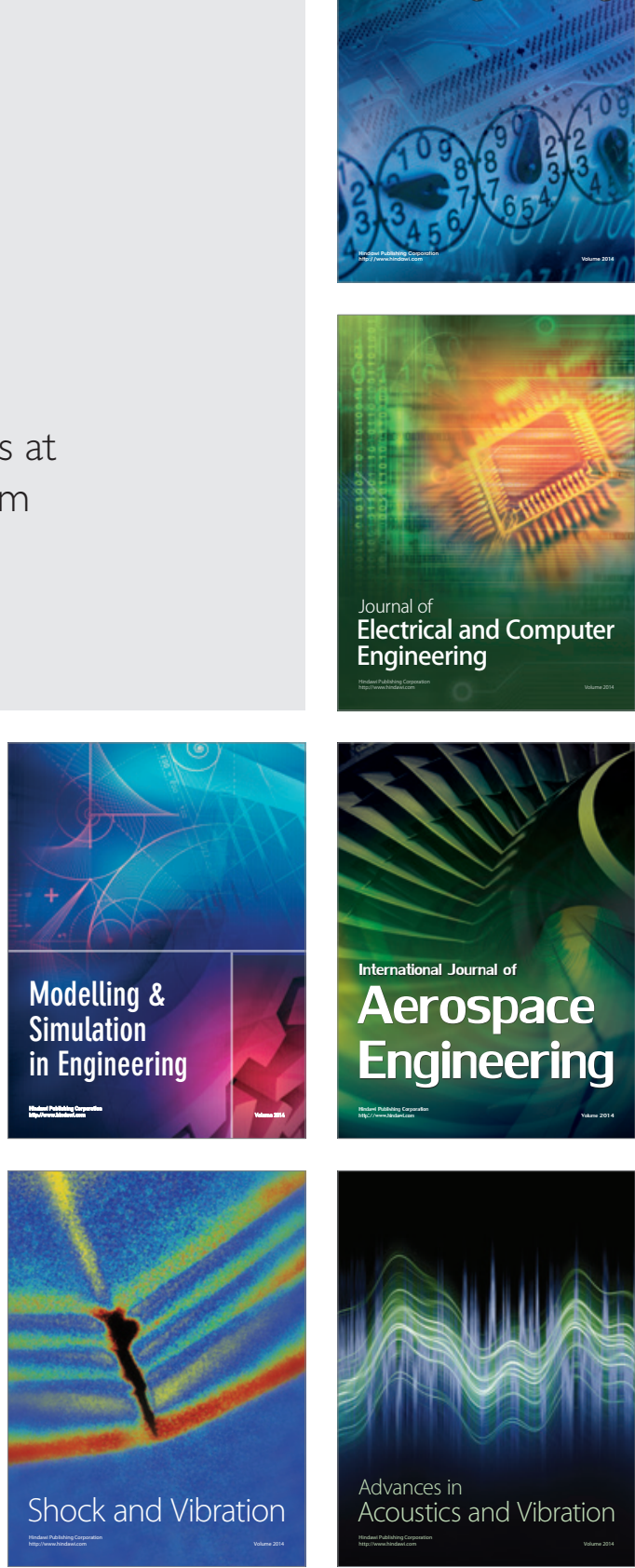